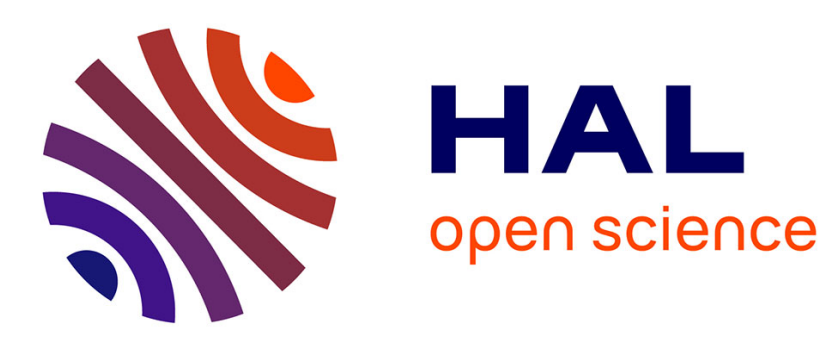

\title{
Opportunities in Higher Education: An Application to France
}

Magali Jaoul-Grammare, Brice Magdalou

\section{To cite this version:}

Magali Jaoul-Grammare, Brice Magdalou. Opportunities in Higher Education: An Application to France. Annals of Economics and Statistics, 2013, 111/112, pp.295-325. 10.2307/23646335 . hal01935847

\section{HAL Id: hal-01935847 \\ https://hal.science/hal-01935847}

Submitted on 27 Nov 2018

HAL is a multi-disciplinary open access archive for the deposit and dissemination of scientific research documents, whether they are published or not. The documents may come from teaching and research institutions in France or abroad, or from public or private research centers.
L'archive ouverte pluridisciplinaire HAL, est destinée au dépôt et à la diffusion de documents scientifiques de niveau recherche, publiés ou non, émanant des établissements d'enseignement et de recherche français ou étrangers, des laboratoires publics ou privés. 


\title{
Opportunities in Higher Education: An Application to France*
}

\author{
Magali Jaoul-Grammare ${ }^{\dagger}$ and Brice Magdalou ${ }^{\ddagger}$
}

\author{
Forthcoming in \\ Annals of Economics and Statistics \\ Number 111-112, July-December 2013
}

\begin{abstract}
This paper first sets out criteria to evaluate the inequality of opportunity in higher education. We propose a two-level classification by distinguishing the categorial and the counterfactual approaches. For each approach we consider dominance quasi-orderings and inequality measures. We then apply these criteria to the French higher education system by comparing the situations in 1992 and 2004. Our main findings suggest: (i) that there is inequality of opportunity in each of the two years; and (ii) that the inequality of opportunity tends to increase during the reporting period, especially the opportunity to graduate in the lowest and highest levels of education.
\end{abstract}

JEL Classification Numbers: I23, D63.

Keywords: Higher education, equality of opportunity, responsibility-sensitive egalitarianism, bidimensional stochastic dominance, divergence measures.

* The paper forms part of the research project The Multiple Dimensions of Inequality (Contract No. ANR 2010 BLANC 1808) of the French National Agency for Research whose financial support is gratefully acknowledged. We are indebted to an associate editor and two anonymous referees whose comments have helped us to substantially improve the paper. We also would like to thank Nathalie Colombier, Joël Hellier, David Masclet and Patrick Moyes for very useful discussions, comments or suggestions. The CEREQ database "Générations 1992 et 2004" was used in the empirical part of the paper. We thank the Centre Maurice Hallbachs for access to this database.

$\dagger$ BETA, CNRS, Université de Strasbourg, 61 avenue de la Forêt Noire, F-67085 Strasbourg Cédex, France. E-mail: jaoulgrammare@beta-cnrs.unistra.fr.

¥ LAMETA, Université Montpellier 1, UFR d'économie, rue R. Dugrand, CS 79606, F-34960 Montpellier, France. E-mail: bricemagdalou@lameta.univ-montp1.fr. Tél: (+33) (0)4344324 44. Fax: (+33) (0)434432461. Corresponding author. 


\section{Introduction}

Any education system has to promote equality of opportunity with regard to educational achievement. This is usually described as a prerequisite for social justice, and as the main factor in intergenerational mobility. Equality of opportunity in education means that the characteristics of the individual which are beyond her own control, such as her family background, must not affect her educational achievement. At the least, education policies should ensure compensation for disabilities, regardless of their nature, for which the individual cannot be held responsible. A good illustration is the so-called "assouplissement de la carte scolaire" in France. This education system reform, which has allowed greater flexibility in the choice of school from the 2009 academic year onwards, was presented with the following objective: "Allowing parents to choose the educational institution for their children, is a way of promoting equality of opportunity as well as social diversity within these institutions." 1

Equality of opportunity tends to be used as a substitute for pure egalitarianism in the modern views on justice. This approach builds on the work of Rawls (1971) with the notions of equality of the fundamental rights and equal access to primary goods. It has been supplemented by other contributions, among of them Dworkin (1981a,b), Sen (1985), Arneson (1989, 1990), Cohen (1989), or more recently Roemer (1998) and Fleurbaey (2008). Although several definitions exist, this principle is structured around two main concerns: the necessity to take into account individual responsibilities and the respect of freedom of choice. The individual is held partially responsible for her own outcomes, and inequality due to responsibility is not considered to be unfair. In contrast, inequality related to factors beyond the individual's control is described as socially undesirable. In such cases, full compensation is required.

The aim of this paper is twofold. First, we set out criteria to evaluate the inequality of opportunity in higher education. ${ }^{2}$ One may want to answer the following questions: (i) is there inequality of opportunity in this particular higher education system? has the situation improved over the last few years? is inequality of opportunity greater in France than in other countries? Hence, suitable criteria are required to assess inequality of opportunity within a distribution of educational outcomes, and others to compare the opportunities between such distributions. Most of the criteria we present already exist in the literature on income inequality and social welfare measurement. We propose a two-level classification by distinguishing the categorial and counterfactual approaches (see section 2 for more details). In the second part of the paper, we investigate the case of France by comparing the situations in 1992 and 2004. We use data collected by the French institute CEREQ (Centre d'Étude et de REcherche sur les

1 http://www.education.gouv.fr/cid5509/assouplissement-de-la-carte-scolaire.html

2 An exhaustive survey of the different approaches dealing with inequality of opportunity is provided by Ramos and Van de gaer (2012). 
Qualifications).

The appropriateness of the theories which define equality of opportunity as a principle of justice, is sometimes called into question as regards education. As rightly mentioned by De Villé (2003), a distinction between the factors for which the individual is held responsible and the others - respectively efforts and circumstances in the text - is necessarily ambiguous when we deal with education. In primary and secondary schools, all the factors which impact educational achievement can be described as circumstances. Indeed, in view of their young age, one may consider that children cannot be held responsible whatever their actions at school. However these arguments, in a narrow sense, do not apply in higher education where A student enters the system as an adult. We agree with Peragine and Serlenga (2008), assuming that a part of the outcome in higher education is within the individual's control.

Several papers dealing with equality of opportunity in education exist in the literature. Brunello and Checchi (2007) looked into whether the interaction between family background and secondary school tracking, coupled with the fact that the students are allocated to different tracks, affects human capital accumulation. Waltenberg and Vandenberghe (2007) evaluated the education expenses which would be necessary in order to eradicate inequality of opportunity in Brazil. Based on a study on 54 countries, Schutz et al. (2008) investigated the interaction between school achievement and students' family backgrounds, and then analysed the effect of education policies on the educational opportunities. The interaction between school achievement and family background has been corroborated by many other empirical studies, in particular Machin and Vignoles (2004), Jaoul-Grammare (2007), Carneiro (2008) or Heineck and Riphahn (2009). Lastly, and closer to our own work, Peragine and Serlenga (2008) propose a theoretical approach to evaluate the inequality of opportunity in higher education. These authors appeal to dominance criteria consistent with a utilitarian social welfare function, initially introduced in the literature [on the measurement of income inequality] by Peragine (2004). These criteria form part of the approach called categorial in this paper.

Our results tend to confirm that some factors, beyond the individual's control such as, for instance, family background or gender, have a significant influence on student success in the French higher education system. Even more alarming is the fact that the situation has not really improve between 1992 and 2004. While none of our criteria conclude that the situation was unambiguously better in 2004 than in 1992, some point to a deterioration in the system. We find that it is more and more difficult for students with unfavourable family characteristics to get through the first year of the Licence degree. Even though the proportion of the students achieving an intermediate university degree slightly increased - which is not the case for the rest of the population - the highest degrees, such as Ph.D., remain much more accessible for students with favourable family characteristics. All in all, one is inclined to conclude that inequality of 
opportunity increased during the period.

The rest of the paper is organized as follows. We discuss in Section 2 the main issues in assessing inequality of opportunity in higher education, and we present our methodological choices. Having set out the general notation, we present in Section 3 some inequality criteria which are traditionnally used to compare distributions. Section 4 is then devoted to the categorial approach. We first introduce dominance criteria specifically suited to the evaluation of inequality of opportunity in higher education. We follow successively the within-effort and between-type directions. The generalized entropy indices are then presented as admissible candidates for evaluating inequality of opportunity, advoking its additive decomposability structure. Section 5 is concerned with the counterfactual approach. We first present the way to define the fair outcome distribution, with regard to individual characteristics and the actual distribution. We then provide some criteria which extend, respectively, the relative Lorenz criterion, the Gini index and the generalized entropy indices. Section 6 presents the data and some descriptive satistics. We gather in Section 7 the results concerning the categorial and counterfactual approaches, while Section 8 concludes.

\section{Issues and Methodological Choices}

The evaluation of the equality of opportunity in the context of higher education raises particular difficulties. In this section we discuss some of them, as well as the choices made. Another objective of this section is to clarify the connections with the existing literature.

A binary separation between efforts and circumstances? According to the ethics of responsibility, individual's efforts are under her own responsibility, and circumstances have to be fully compensated for. From an empirical point of view, however, this separation is obviously questionable. First, some factors are neither pure circumstances, nor pure efforts. For example, the number of hours studying at home per day can be imputed without possible distinction to a student's personal involvement, or to the material conditions she has access to. Another difficulty, and arguably the greatest, is the treatment of so-called innate ability, or talent, in the case of education. This factor is indisputably a circumstance, because it is not a matter of choice. Nevertheless, the issue of its compensation remains an open debate. Following the Marxist doctrine, we may wish for full compensation, arguing that "from each according to their ability, to each according to their needs". On the other hand, if we embrace liberal ethics, compensation can be viewed as exploitation of the most talented individuals. A final issue deals with unobservable factors. Again, because we cannot precisely assess the impact on school achievement and the interrelations of these factors, it seems difficult to associate these with either efforts or circumstances. 
Different strategies have been suggested to tackle the issue of the responsibility cut. One way, initiated by Devooght (2008), consists in arranging the observable factors from maximal to minimal responsibility, and then considering different scenarios ranging from the most egalitarian - where only the most obvious efforts are not compensated for - to the most libertarian. The unobservable factors are then aggregated in a residual component and treated either as a responsibility or a compensation variable. An alternative, recently proposed by Ooghe (2010), involves assuming partial compensation of the variables, which are not unambiguously classified as circumstances or efforts. Here, a degree of compensation has to be fixed for each unclassified variable.

In this paper, we first assume a partial observability of the circumstances. For these variables only, we impose full compensation. Due to the unobservability of some variables, the criteria, or measures, we propose are not sufficient to guarantee full equality of opportunity. Nevertheless, equality of opportunity in the sense of our criteria is a necessary condition. All the unobservable factors - particularly innate ability for education - are left to the individual's responsibility. Our approach is therefore that of minimal compensation. Among all the observable variables which characterize an individual, we then assume that the most offensive circumstance is related to the social status of her parents. All our criteria consider it as a source of compensation. For the other observable variables, we follow Devooght's strategy, by investigating different compensation scenarios.

Categorial or counterfactual approach? The distinction between fair and unfair inequalities has been the subject of much attention in contemporary theories of justice. We propose a two-level classification. First, we bring together under the term categorial approach all the theories which assume explicitly or implicitly (i) that a finite number of categories of persons, sharing common characteristics, can be observed in the society; and (ii) that all the categories can be ordered on the basis of normative considerations.

- Roemer's contribution (Roemer, 1993, 1998) is the first example. Considering that individuals with the same circumstances are of the same type, Roemer proposes to identify the efforts of an individual from her rank in the quantile (percentile) distribution of outcomes, conditional on her type. In this context, a category consists of all the individuals with the same rank - whatever the type - who are assumed by definition to exert the same effort. The higher the rank which identifies the category, the greater the efforts. Equality of opportunity is achieved if and only if there is no inequality of outcome within each category. This will be referred to as within-effort opportunity.

- The literature focusing on opportunity sets, inspired by Van de gaer (1993), is another example. Now a category is a type (in the previous sense), or equivalently the set of individuals with the same circumstances. Each category is characterized by an opportunity set, assimilated with 
its mean outcome. Hence, in this case, the categories can be ordered on the basis of their opportunity sets. Equality of opportunity is achieved if and only if there is no outcome inequality between the categories. This will be referred as between-type opportunity.

To sum up, an ordering of the effort levels is required in Roemer's setting, whereas an ordering of the circumstances is necessary in Van de gaer's setting. Ooghe et al. (2007) investigated these categorial approaches, their normative foundations and their differences.

Alternative theories appeal to normative views for defining what is meant by a fair outcome for an individual, taking into account her actual outcome and her characteristics profile (circumstances and efforts). This is called, in the present paper, the counterfactual approach. From the actual outcome distribution, the main objective is thus to delineate the fair distribution. An example of a normative principle is the conditionally egalitarian mechanism. This requires that differences in outcome due to the individual exercise of responsibility, have to be fully respected in the fair distribution (see Fleurbaey, 2008). Then the more the actual distribution is distant from the fair distribution, the larger the inequality of opportunity. ${ }^{3}$ This approach has been used by Bourguignon et al. (2007), Devooght (2008), Checchi and Peragine (2010) and Almas et al. (2011), among others, to evaluate the inequality of opportunity in income.

To get an accurate picture of the opportunities in higher education in France and of their evolution, we deemed it appropriate to apply both the categorial and the counterfactual approaches. The counterfactual approach has the advantage of analyzing the situation of individuals independently from each other, defining what a fair outcome could be for anyone. However, for each individual, we have to know precisely how her characteristics affect her actual outcome. This requires a lot of information, and the reliability of the results depends drastically on the quality of the estimation procedures. The categorial approach does not require as much information, as long as categories of persons having the same characteristics can be constituted. As a counterpart, strong normative assumptions are required to define an ordering on the categories, and we have to restrict attention to a small number of categories. For all these reasons, it is difficult to say that one approach is better than another.

Inequality indices or dominance criteria? So far, the current practice consists in ranking the distributions according to the values given by a particular inequality index. Unfortunately, the rankings thus obtained are totally determined by the normative views encapsulated in the index, and different indices can provide different rankings. The dominance approach has the advantage of seeking unanimity among a large class of indices and, consequently, among a set of alternative normative views. In a normative sense, a dominance criterion is more transparent. However, the substitution of a dominance criterion for an inequality index can be costly. Indeed, it only provides a partial ranking of the distributions, so that inconclusiveness may

3 Note that, by construction, the mean outcome in the fair and the actual distributions are usually equal. 
occur. Whatever the approach, categorial (within-effort or between-type opportunity) or counterfactual, we apply both dominance criteria and inequality indices. Most of the dominance criteria we consider have been already introduced by Peragine (2004) and Almas et al. (2011) in the first and second approaches, respectively.

\section{Framework and Notation}

We now present the main notation used throughout the paper. Let $\mathbb{N}$ denote the set of positive integers and $\mathbb{R}_{+}$the set of all non-negative real numbers. We consider a population $\mathcal{N}:=\{1,2, \ldots, n\}$, consisting of $n \in \mathbb{N}$ individuals having completed their degrees in higher education $(n \geq 2)$. We identify the educational outcome of an individual $i \in \mathcal{N}$ with the highest level of training she had reached when she left higher education, hereafter referred to hereafter as the number of years of higher education. We assume that the educational outcome is determined by her characteristics profile. Some characteristics, called circumstances, are beyond the individual's responsibility. They include, for instance, the social situation or the tutoring abilities of her parents. Some others, such as her own involvement in education, are assumed to be under the control of the individual, and are referred to as efforts. For the individual $i \in \mathcal{N}$, the efforts profile is denoted by $\boldsymbol{e}_{i}:=\left(e_{i}^{1}, e_{i}^{2}, \ldots, e_{i}^{E}\right)$ and the circumstances profile by $\boldsymbol{c}_{i}:=\left(c_{i}^{1}, c_{i}^{2}, \ldots, c_{i}^{C}\right)$ where $E, C \in \mathbb{N}$ are, respectively, the number of efforts and the number of circumstances. The characteristics profile of $i \in \mathcal{N}$ is $\boldsymbol{a}_{i}:=\left(\boldsymbol{e}_{i} ; \boldsymbol{c}_{i}\right)$. We let $\mathscr{D}=\mathscr{D}_{E} \times \mathscr{D}_{C}$, where $\mathscr{D}_{E} \subseteq \mathbb{R}_{+}^{E}$ and $\mathscr{D}_{C} \subseteq \mathbb{R}_{+}^{C}$ indicate the set of all possible characteristics profiles. The (global) characteristics profile for society as a whole is defined by $\boldsymbol{a}:=\left(\boldsymbol{a}_{i}\right)_{i \in \mathcal{N}}$, with $\boldsymbol{a} \in \mathscr{D}^{n}$. We define by $\boldsymbol{x}:=\left(x_{i}\right)_{i \in \mathcal{N}}$ the educational outcome distribution, with mean $\mu(\boldsymbol{x})$, where $x_{i}$ is the educational outcome of individual $i \in \mathcal{N}$. The set of all possible distributions of size $n$ is denoted by $\Omega_{n} \subseteq \mathbb{R}_{+}^{n}$, and the set of all distributions of finite size by $\Omega:=\bigcup_{n=2}^{\infty} \Omega_{n}$. The egalitarian distribution, where all individuals have the mean of $\boldsymbol{x}$, is denoted by $\boldsymbol{\mu}(\boldsymbol{x}):=(\mu(\boldsymbol{x}))_{i \in \mathcal{N}}$.

The information available for the outcome distribution $\boldsymbol{x} \in \Omega$ is captured by its cumulative distribution function, denoted by $F(z)$ for all $z \in \mathbb{R}$. Alternatively the inverse cumulative function, also called the quantile function, defined by $F^{-1}(0):=\inf \{z \in \mathbb{R} \mid F(z)>0\}$ and $F^{-1}(p):=\inf \{z \in \mathbb{R} \mid F(z) \geq p\}$ for all $p \in(0,1]$, can be considered (Gastwirth, 1971). It is a common pratice in empirical studies to divide a distribution $\boldsymbol{x}$ into $M$ quantile groups $(M=10$ for deciles, 100 for centiles, ...), delimited by the abscissae $p_{m}:=m / M$ where $m=0,1, \ldots, M$. For each quantile group $m$, we define the quantile mean by $Q\left(p_{m}\right):=M \int_{p_{m-1}}^{p_{m}} F^{-1}(p) d p$, which corresponds to the mean educational outcome in the quantile (see e.g. Beach et al., 1994, for an application to income distributions). Consequently, the distribution $\boldsymbol{x}$, whatever its size, is represented by a list of $M$ educational outcomes, namely the quantile means. 
The equality of opportunity measures we present in this paper can be viewed as extensions of standard inequality measures. In the inequality measurement literature, a current pratice consists in comparing the relative Lorenz curves of the distributions under consideration. The relative Lorenz curve of the distribution $\boldsymbol{x} \in \Omega$ is defined by $R L\left(p_{m}\right):=\sum_{j=1}^{m} Q\left(p_{j}\right) /(M \mu(\boldsymbol{x}))$, for all $m=1,2, \ldots, M$. The following quasi-ordering is obtained: ${ }^{4}$

Definition 1 (RL). Given two distributions $\boldsymbol{x}^{\star}, \boldsymbol{x}^{\circ} \in \Omega$, we will say that $\boldsymbol{x}^{\star}$ relative Lorenz dominates $\boldsymbol{x}^{\circ}$, which we write as $\boldsymbol{x}^{\star} \succeq_{R L} \boldsymbol{x}^{\circ}$, if and only if $R L^{\star}\left(p_{m}\right) \geq R L^{\circ}\left(p_{m}\right)$ for all $m=$ $1,2, \ldots, M$.

Instead of quasi-orderings, it is possible to rank the distributions according to the values given by particular indices. For $\boldsymbol{x} \in \Omega$, the Gini index is defined by:

$$
G(\boldsymbol{x}):=\frac{1}{2 n(n-1) \mu(\boldsymbol{x})} \sum_{i \in \mathcal{N}} \sum_{j \in \mathcal{N}}\left|x_{i}-x_{j}\right| .
$$

We also consider the generalized entropy indices. We first present a larger class introduced by Magdalou and Nock (2011), from which the entropies can be obtained as a particular case. ${ }^{5}$ We define by $\mathcal{P}:=\left\{(\boldsymbol{x}, \boldsymbol{y}) \in \Omega_{n} \times \Omega_{n} \mid n \geq 2\right\}$ the set of pairs of distributions $(\boldsymbol{x}, \boldsymbol{y})$ having the same size. Letting $(\boldsymbol{x}, \boldsymbol{y}) \in \mathcal{P}$, this class is defined by:

$$
I_{r}(\boldsymbol{x}, \boldsymbol{y}):=\frac{D_{r}(\boldsymbol{x}, \boldsymbol{y})}{n \mu(\boldsymbol{x})^{r}},
$$

where:

$$
D_{r}(\boldsymbol{x}, \boldsymbol{y}):= \begin{cases}\frac{1}{n r(r-1)} \sum_{i \in \mathcal{N}}\left[x_{i}{ }^{r}+(r-1) y_{i}{ }^{r}-r x_{i} y_{i}{ }^{r-1}\right], & \text { if } r \neq 0,1, \\ \frac{1}{n} \sum_{i \in \mathcal{N}}\left[x_{i} \ln \left(x_{i} / y_{i}\right)\right], & \text { if } r=1, \\ \frac{1}{n} \sum_{i \in \mathcal{N}}\left[x_{i} / y_{i}-\ln \left(x_{i} / y_{i}\right)-1\right], & \text { if } r=0 .\end{cases}
$$

It is characterized by a unique parameter $r$, which determines the degree of inequality aversion. The generalized entropy class for a distribution $\boldsymbol{x}$ corresponds, with a slight abuse of notation, to $I_{r}(\boldsymbol{x})=I_{r}(\boldsymbol{x}, \boldsymbol{\mu}(\boldsymbol{x}))$. In our context, an inequality measure - quasi-ordering or index - can be applied, only if we assume that all the inequalities are offensive. In the following we provide alternatives, for which the inequalities arising from differences in responsibility are not evaluated as unfair.

${ }^{4}$ A quasi-ordering $\succeq$ is a transitive and reflexive binary relation. The symmetric and asymmetric parts of $\succeq$ are denoted, respectively, by $\sim$ and $\succ$.

5 The general class will be applied in the counterfactual approach. 


\section{Opportunities by the Categorial Approach}

\subsection{The Specific Framework}

As already emphasized, the categorial approach requires that an ordering, either according to the efforts (Roemer, 1993, 1998) or according to the circumstances (Van de gaer, 1993), is given. We present criteria in both directions. From now on, we assume that: (i) the circumstances are partially observable, and that (ii) no information is available for the efforts. The subset of individuals having a common profile $c$ of observable circumstances is indicated by $\mathcal{N}(\boldsymbol{c}):=\left\{i \in \mathcal{N} \mid \boldsymbol{c}_{i}=\boldsymbol{c}, \boldsymbol{c} \in \mathscr{D}_{C}\right\}$. We say that individuals in $\mathcal{N}(\boldsymbol{c})$ are of the same type. The number of individuals with type $\boldsymbol{c}$ is denoted by $n(\boldsymbol{c}):=\# \mathcal{N}(\boldsymbol{c})$. The educational outcome distribution $\boldsymbol{x}$ conditional on type $\boldsymbol{c}$ is represented by $(\boldsymbol{x} \mid \boldsymbol{c}):=\left(x_{i}\right)_{i \in \mathcal{N}(\boldsymbol{c})}$. The cumulative distribution function conditional on type $\boldsymbol{c}$ is indicated by $F(z \mid \boldsymbol{c})$ for all $z \in \mathbb{R}$. The quantile function conditional on $\boldsymbol{c}$, is defined by $F^{-1}(0 \mid \boldsymbol{c}):=\inf \{z \in \mathbb{R} \mid F(z \mid \boldsymbol{c})>0\}$ and $F^{-1}(p \mid \boldsymbol{c}):=\inf \{z \in \mathbb{R} \mid F(z \mid \boldsymbol{c}) \geq p\}$ for all $p \in(0,1]$. Finally, $Q\left(p_{m} \mid \boldsymbol{c}\right):=M \int_{p_{m-1}}^{p_{m}} F^{-1}(p \mid \boldsymbol{c}) d p$ represent the quantile mean conditional on $\boldsymbol{c}$.

We assume that a finite number $K \in \mathbb{N}$ of possible types exists, so that $\left(\boldsymbol{x} \mid \boldsymbol{c}^{k}\right)$ corresponds to the educational outcome distribution $\boldsymbol{x}$ conditional on type $\boldsymbol{c}^{k}$, with $k=1,2, \ldots, K$. The following matrix summarizes the relevant information avalaible for $\boldsymbol{x}$ :

$$
\boldsymbol{Q}:=\left[\begin{array}{cccc}
Q\left(p_{1} \mid \boldsymbol{c}^{1}\right) & Q\left(p_{2} \mid \boldsymbol{c}^{1}\right) & \cdots & Q\left(p_{M} \mid \boldsymbol{c}^{1}\right) \\
Q\left(p_{1} \mid \boldsymbol{c}^{2}\right) & Q\left(p_{2} \mid \boldsymbol{c}^{2}\right) & \cdots & Q\left(p_{M} \mid \boldsymbol{c}^{2}\right) \\
\vdots & \vdots & \ddots & \vdots \\
Q\left(p_{1} \mid \boldsymbol{c}^{K}\right) & Q\left(p_{2} \mid \boldsymbol{c}^{K}\right) & \cdots & Q\left(p_{M} \mid \boldsymbol{c}^{K}\right)
\end{array}\right]
$$

The ratio $n\left(\boldsymbol{c}^{k}\right) / n$ indicates the proportion, over the whole population $\mathcal{N}$, of individuals with type $\boldsymbol{c}^{k}$. This proportion is constant for each element within a line, but may vary within a column. With a slight abuse of notation, we denote by $\left(\boldsymbol{x} \mid \boldsymbol{c}^{k}\right)$ with mean $\mu\left(\boldsymbol{x} \mid \boldsymbol{c}^{k}\right)$ the $k^{\text {th }}$ line of $\boldsymbol{Q}$, from now on. Similarly the $m^{\text {th }}$ column of $\boldsymbol{Q}$ is denoted by $(\boldsymbol{x} \mid m)$, with mean $\mu(\boldsymbol{x} \mid m) .{ }^{6}$

\subsection{Stochastic Dominance}

We turn now to opportunity quasi-orderings, assuming that $\boldsymbol{Q}$ in (4.1) is an admissible list of representative educational outcomes for society. We first analyze the equality of opportunity within a distribution, which requires that two individuals having the same circumstances and efforts, should have the same outcome. We define:

6 Note that $\mu\left(\boldsymbol{x} \mid \boldsymbol{c}^{k}\right)$ is an unweighted mean. On the other hand, in order to compute $\mu(\boldsymbol{x} \mid m)$, the quantile means $Q\left(p_{m} \mid \boldsymbol{c}^{k}\right)$ for $k$ equals 1 to $K$ have to be weighted by the corresponding $n\left(\boldsymbol{c}^{k}\right) / n$. 
Definition 2 (Inequality of Opportunity Within a Distribution). Given a distribution $\boldsymbol{x} \in \Omega$, we will say that there is inequality of opportunity within $\boldsymbol{x}$, if and only if there exists an indexation $\left\{\boldsymbol{c}^{1}, \boldsymbol{c}^{2}, \ldots, \boldsymbol{c}^{K}\right\}$ of the $K$ types such that $Q\left(p_{m} \mid \boldsymbol{c}^{k+1}\right) \geq Q\left(p_{m} \mid \boldsymbol{c}^{k}\right)$ for all $m=1,2, \ldots, M$, and all $k=1,2, \ldots, K-1$, with a strict inequality for at least one $k$.

Equivalently, there is inequality of opportunity within a distribution if the lines of matrix $Q$ are ordered. This means that a hierarchy exists between the types, so that the observable circumstances have an impact on the educational outcome. Following Lefranc et al. (2009, Prop. 1, p. 1193), a necessary condition to ensure equality of opportunity - weaker than the standard one which requires full observability of efforts and circumstances, but implementable in pratice - is that $Q\left(p_{m} \mid \boldsymbol{c}^{k+1}\right)=Q\left(p_{m} \mid \boldsymbol{c}^{k}\right)$ for all $m$ and all $k$ in the previous definition. ${ }^{7}$ It is also a sufficient condition, but only under restrictive considerations, one of which is that the outcome function is increasing in effort (Lefranc et al., 2009).

In order to compare two distributions in terms of inequality of opportunity, other restrictions are required. We first focus on the usual Roemer approach (Roemer, 1993, 1998), assuming that efforts can be approximated by the individual's rank in the conditional quantile function. Precisely, each column $m(m=1,2, \ldots, M)$ of the matrix $\boldsymbol{Q}$ represents a particular level of effort, so that an individual with type $\boldsymbol{c}^{k}$ in $Q\left(p_{m} \mid \boldsymbol{c}^{k}\right)$ is described as providing the same efforts as an individual with type $\boldsymbol{c}^{l}$ in the corresponding quantile $Q\left(p_{m} \mid \boldsymbol{c}^{l}\right)$. Moreover the higher $m$ is, the greater the efforts. Thus an ordering is assumed for the efforts. The quasi-ordering we propose for this approach is called within-effort opportunity $R L$, according to which each column of the matrix $\boldsymbol{Q}$ is treated as a distribution.

Definition 3 (Within-Effort Opportunity RL). Given two distributions $\boldsymbol{x}^{\star}, \boldsymbol{x}^{\circ} \in \Omega$, we will say that $\boldsymbol{x}^{\star}$ relative Lorenz dominates $\boldsymbol{x}^{\circ}$ in the within-effort opportunity sense, which we write $\boldsymbol{x}^{\star} \succeq_{E R L} \boldsymbol{x}^{\circ}$, if and only if $\left(\boldsymbol{x}^{\star} \mid m\right) \succeq_{R L}\left(\boldsymbol{x}^{\circ} \mid m\right)$ for each column $m=1,2, \ldots, M{ }^{8}$

An alternative to Roemer's approach, in terms of opportunity sets, requires an ordering on the circumstances (Van de gaer, 1993). However, in this case, no assumptions are made about the efforts. The following quasi-ordering is called between-type opportunity $R L$.

It is an implementable version - i.e., applicable to the comparison of distributions with

7 Lefranc et al. (2009) apply the criterion to the distribution function instead of the quantile function. Nevertheless, by the equivalence between the - first order - stochastic and inverse stochastic dominance criteria, these approaches are identical.

8 Precisely, we have $\left(\boldsymbol{x}^{\star} \mid m\right) \succeq_{R L}\left(\boldsymbol{x}^{\circ} \mid m\right)$ if and only if $E R L^{\star}\left(p_{m} ; k\right) \geq E R L^{\circ}\left(p_{m} ; k\right)$ for all $k=1,2, \ldots, K$, where $\operatorname{ERL}\left(p_{m} ; k\right)$ is the sum over $h$ of the $k$ lowest quantile means $Q\left(p_{m} \mid \boldsymbol{c}^{h}\right)$ weighted by $n\left(\boldsymbol{c}^{h}\right) / n$, and deflated by $\mu(\boldsymbol{x} \mid m)$. We emphasize that this approach does not require a rank on the possible circumstances, which is why it does not matter that the $k$ lowest quantile means, used to compute $E R L^{\star}\left(p_{m} ; k\right)$, do not involve the same types as those used to compute $E R L^{\circ}\left(p_{m} ; k\right)$. 
different sizes - of a quasi-ordering introduced by Peragine (2004). We recall that $\mu\left(\boldsymbol{x} \mid \boldsymbol{c}^{k}\right)$ is the mean of the educational outcome distribution for type (or line) $\boldsymbol{c}^{k}$.

Definition 4 (Between-Type Opportunity RL). Given two distributions $\boldsymbol{x}^{\star}, \boldsymbol{x}^{\circ} \in \Omega$, we will say that $\boldsymbol{x}^{\star}$ relative Lorenz dominates $\boldsymbol{x}^{\circ}$ in the between-type opportunity sense, which we write $\boldsymbol{x}^{\star} \succeq_{T R L} \boldsymbol{x}^{\circ}$, if and only if: 9

(i) there exists an indexation $\left\{\boldsymbol{c}^{1}, \boldsymbol{c}^{2}, \ldots, \boldsymbol{c}^{K}\right\}$ of the $K$ types such that $\mu\left(\boldsymbol{x} \mid \boldsymbol{c}^{k+1}\right) \geq \mu\left(\boldsymbol{x} \mid \boldsymbol{c}^{k}\right)$, for all $k=1,2, \ldots, K-1$, common for the distributions $\boldsymbol{x}=\boldsymbol{x}^{\star}$ and $\boldsymbol{x}=\boldsymbol{x}^{\circ}$.

(ii) $\left(\mu\left(\boldsymbol{x}^{\star} \mid \boldsymbol{c}^{k}\right)\right)_{k=1, \ldots, K} \succeq_{R L}\left(\mu\left(\boldsymbol{x}^{\circ} \mid \boldsymbol{c}^{k}\right)\right)_{k=1, \ldots, K}$.

Hence, it is assumed that the circumstance profiles can be ordered on the basis of their corresponding [conditional] means. The standard relative Lorenz criterion is then applied to this ordered list of conditional means.

Even if a quasi-ordering is transparent from a normative point of view, it only provides a partial ranking of the distributions under comparison (inconclusiveness may occur). In the following subsection, we investigate the measurement of inequality of opportunity, through the use of aggregate inequality indices.

\subsection{Indices of Inequality of Opportunity}

Following the categorial approach, the matrix $\boldsymbol{Q}$ in equation (4.1) captures all the pertinent information of an educational outcome distribution $\boldsymbol{x}$. With this in mind, several indices can be applied to evaluate the inequality of opportunity. For example, Checchi and Peragine (2010) use the mean logarithmic deviation index. ${ }^{10}$ In this paper we apply a standard class of indices, the so-called generalized entropy family. One reason is that this approach makes sense, as argued later, in both the categorial and counterfactual approaches. This class was presented in subsection 3, recalling that it can be written $I_{r}(\boldsymbol{x})=I_{r}(\boldsymbol{x}, \boldsymbol{\mu}(\boldsymbol{x}))$.

The additive decomposability property of the generalized entropy indices is used to dissociate the inequality due to initial circumstances from the inequality due to efforts. Two types of decomposition are possible. According to the within-effort approach, the inequality of opportunity results from differences in outcomes within each column of $\boldsymbol{Q}$, where all individuals are assumed

9 Precisely, $\left(\mu\left(\boldsymbol{x}^{\star} \mid \boldsymbol{c}^{k}\right)\right)_{k=1, \ldots, K} \succeq_{R L}\left(\mu\left(\boldsymbol{x}^{\circ} \mid \boldsymbol{c}^{k}\right)\right)_{k=1, \ldots, K}$ if and only if $T R L^{\star}\left(\boldsymbol{c}^{k}\right) \geq T R L^{\circ}\left(\boldsymbol{c}^{k}\right)$ for all $k=$ $1,2, \ldots, K$, where $T R L\left(\boldsymbol{c}^{k}\right)$ is the sum over $h$ of the $k$ lowest means $\mu\left(\boldsymbol{x} \mid \boldsymbol{c}^{h}\right)$ weighted by $n\left(\boldsymbol{c}^{h}\right) / n$, and deflated by $\mu(\boldsymbol{x})$.

${ }^{10}$ This choice is motivated by the decomposability property which characterizes this index, namely pathindependent decomposability, initially explored by Foster and Shneyerov (2000). 
to make the same efforts. One obtains the first decomposition of the global inequality evaluated by $I_{r}(\boldsymbol{x})$, into an unfair component $I_{r}^{U_{1}}(\boldsymbol{x})$ and a fair component $I_{r}^{F_{1}}(\boldsymbol{x})$, such that:

$$
I_{r}(\boldsymbol{x})=I_{r}^{U_{1}}(\boldsymbol{x})+I_{r}^{F_{1}}(\boldsymbol{x})=\sum_{m=1}^{M} w_{r}^{1}(\boldsymbol{x}) I_{r}(\boldsymbol{x} \mid m)+\sum_{m=1}^{M} w_{r}^{1}(\boldsymbol{x}) I_{r}(\mu(\boldsymbol{x} \mid m), \mu(\boldsymbol{x})),
$$

where $w_{r}^{1}(\boldsymbol{x}):=\mu(\boldsymbol{x} \mid m)^{r} /\left(M \mu(\boldsymbol{x})^{r}\right)$. Note that the component of unfair inequality reflects the within-effort inequality. Indeed, $I_{r}(\boldsymbol{x} \mid m)$ computes the inequality within effort (or column) $m$. The other component, $I_{r}(\mu(\boldsymbol{x} \mid m), \mu(\boldsymbol{x}))$, quantifies the distance between the mean outcome $\mu(\boldsymbol{x} \mid m)$, which corresponds to the effort $m$, and the global mean $\mu(\boldsymbol{x})$. Since the efforts do not have to be compensated for, this last component measures the part of fair inequality.

Another decomposition can be obtained by applying the between-type approach. Here, the opportunity of one type $k$ is evaluated by the mean outcome it achieves, $\mu\left(\boldsymbol{x} \mid \boldsymbol{c}^{k}\right)$. The inequality of opportunity follows from the differences in such conditional mean outcomes. Conversely, the inequality within a line in $\boldsymbol{Q}$ is described as fair because it results from differences in effort. The second decomposition is obtained:

$$
I_{r}(\boldsymbol{x})=I_{r}^{F_{2}}(\boldsymbol{x})+I_{r}^{U_{2}}(\boldsymbol{x})=\sum_{k=1}^{K} w_{r}^{2}(\boldsymbol{x}) I_{r}\left(\boldsymbol{x} \mid \boldsymbol{c}^{k}\right)+\sum_{k=1}^{K} w_{r}^{2}(\boldsymbol{x}) I_{r}\left(\mu\left(\boldsymbol{x} \mid \boldsymbol{c}^{k}\right), \mu(\boldsymbol{x})\right),
$$

where $w_{r}^{2}(\boldsymbol{x}):=\left(n\left(\boldsymbol{c}^{k}\right) / n\right)\left(\mu\left(\boldsymbol{x} \mid \boldsymbol{c}^{k}\right) / \mu(\boldsymbol{x})\right)^{r}$. The first component aggregates the inequalities within each line of $\boldsymbol{Q}$, which is considered to be fair. The second component reflects the betweentype inequality - namely the distance between the conditional means $\mu\left(\boldsymbol{x} \mid \boldsymbol{c}^{k}\right)$ and the global mean $\mu(\boldsymbol{x})$ - which is assumed to be unfair.

\section{Opportunities by the Counterfactual Approach}

\subsection{The Specific Framework}

We first recall that society is represented by a global characteristics profile $\boldsymbol{a}:=\left(\boldsymbol{a}_{i}\right)_{i \in \mathcal{N}} \in \mathscr{D}^{n}$, where $\boldsymbol{a}_{i}:=\left(\boldsymbol{e}_{i} ; \boldsymbol{c}_{i}\right)$ is the characteristics profile - efforts and circumstances - of the individual $i \in \mathcal{N}$. Again, $\boldsymbol{x}:=\left(x_{i}\right)_{i \in \mathcal{N}}$ denotes the educational outcome distribution, with mean $\mu(\boldsymbol{x})$. However, now it is assumed that the educational outcome is a function of the individual's characteristics such that, for all $i \in \mathcal{N}$, an outcome $x\left(\boldsymbol{a}_{i}\right)$ is associated to the profile $\boldsymbol{a}_{i}$. ${ }^{11}$ For notational convenience, we let $x_{i}=x\left(\boldsymbol{a}_{i}\right)$.

${ }^{11}$ Note that $x$ is an individualistic application - in the sense that it only depends on the personal profile - but common to all individuals. 
The main feature of the counterfactual approach is to assume that a fair outcome distribution, which ensures equal opportunities for everyone, can be constructed from any actual distribution $\boldsymbol{x}$. The fair educational outcome is an application which depends on the individual's characteristics, but also on the characteristics of the others. Precisely, it is assumed that a fair outcome $y_{i}(\boldsymbol{a})$ can be obtained from $\boldsymbol{a}$ for each individual $i \in \mathcal{N}$. Based on the work of Fleurbaey (1994, 1995a,b,c), Bossert (1995) and Bossert and Fleurbaey (1996) in income inequality, where redistribution mechanisms are used to construct the fair distribution starting with the actual disitribution, we present some usual conditions to be imposed on the applications $y_{i}$.

Following the anonymity condition, it is required that two individuals with exactly the same profiles should have the same outcome in the fair distribution. Another condition, called outcome balance, assumes that the fair distribution preserves the mean of the actual distribution.

ANONYMity. $\forall \boldsymbol{a} \in \mathscr{D}^{n}, \forall i, j \in \mathcal{N}, \boldsymbol{a}_{i}=\boldsymbol{a}_{j} \Rightarrow y_{i}(\boldsymbol{a})=y_{j}(\boldsymbol{a})$.

Outcome Balance. $\forall \boldsymbol{a} \in \mathscr{D}^{n}, \sum_{i \in \mathcal{N}} y_{i}(\boldsymbol{a})=\sum_{i \in \mathcal{N}} x\left(\boldsymbol{a}_{i}\right)$.

In the fair distribution, the inequality due to circumstances has to be compensated for. Many compensation principles, sometimes conflicting, exist in the literature. In this paper we consider conditional egalitarianism. This principle puts forward the responsibility dimension of the individual's choices, so that inequalities not correlated to circumstances are maintained in the fair distribution. 12

Conditional Egalitarianism. $\forall \boldsymbol{a} \in \mathscr{D}^{n}, \forall i, j \in \mathcal{N}, \boldsymbol{c}_{i}=\boldsymbol{c}_{j} \Rightarrow y_{i}(\boldsymbol{a})-x\left(\boldsymbol{a}_{i}\right)=y_{j}(\boldsymbol{a})-x\left(\boldsymbol{a}_{j}\right)$.

Following Bossert and Fleurbaey (1996) and Kolm (1996), it is well-known that a fair distribution is consistent with anonymity, outcome balance and conditional egalitarianism if and only if it is obtained from the actual distribution by a transformation called conditionally egalitarian mechanism.

\footnotetext{
${ }^{12}$ Note that the principle of egalitarian-equivalence, for which two individuals with the same efforts should have the same outcome in the fair distribution, can be substituted for conditional egalitarianism. This principle reflects the egalitarian feature of the responsibility-sensitive theories of justice. Nevertheless, it seems to be too demanding in our context. First, we recall that partial observability of the circumstances is assumed, so that some circumstances and efforts are unobservable. As a consequence, we do not have sufficient information to identify two individuals as providing the same efforts. Then, the status of one variable, the innate ability or talents for education - which determines for a substantial part the school achievement - should be handled with caution. Even if it is indisputably a circumstance, the question of its compensation remains controversial. According to the principle of egalitarian-equivalence, any circumstance has to be fully compensated for. This of course applies to the innate ability for education. Nevertheless such a compensation can be viewed as an exploitation of the most talented individuals, and thus perceived as undesirable. Conditional egalitarianism seems to be more suited to the context of higher education.
} 
Definition 5 (Conditionally Egalitarian Mechanism). For all $\boldsymbol{a} \in \mathscr{D}^{n}$ and all $i \in \mathcal{N}$, we have:

$$
y_{i}(\boldsymbol{a})=x\left(\boldsymbol{a}_{i}\right)-x\left(\overline{\boldsymbol{e}}, \boldsymbol{c}_{i}\right)+\frac{1}{n} \sum_{j \in \mathcal{N}} x\left(\overline{\boldsymbol{e}}, \boldsymbol{c}_{j}\right),
$$

where $\overline{\boldsymbol{e}}$ is a reference profile of efforts, arbitrarily chosen.

If an individual is characterized by the reference profile of efforts, then the fair outcome for her corresponds to the mean outcome, in the artificial situation where all individuals have the same reference profile of efforts. Since $x$ is increasing in effort, every increase [resp. decrease] in effort, as compared to the reference profile, implies an increase [resp. decrease] in the fair outcome.

\subsection{Stochastic Dominance}

Society is now characterized by the educational outcome distribution $\boldsymbol{x}:=\left(x_{i}\right)_{i \in \mathcal{N}}$, and the corresponding fair distribution $\boldsymbol{y}:=\left(y_{i}\right)_{i \in \mathcal{N}}$. Since the conditionally egalitarian mechanism we consider is consistent with the outcome balance property, the distributions have the same means. We are now therefore interested in the following set $\overline{\mathcal{P}}:=\left\{(\boldsymbol{x}, \boldsymbol{y}) \in \mathcal{P} \mid \mu(\boldsymbol{x})=\mu(\boldsymbol{y})=\mu, \mu \in \mathbb{R}_{+}\right\}$ of pairs of distributions $(\boldsymbol{x}, \boldsymbol{y})$ having the same size and the same mean. Intuitively, equality of opportunity happens when $\boldsymbol{x}=\boldsymbol{y}$. The more the actual distribution is distant from the fair distribution, the larger the inequality of opportunity.

For a pair of distributions $(\boldsymbol{x}, \boldsymbol{y}) \in \overline{\mathcal{P}}$, Almas et al. (2011) propose to compute the difference $\boldsymbol{z}:=\boldsymbol{x}-\boldsymbol{y}$ and then apply a slightly modified version of the relative Lorenz criterion to this new distribution. This criterion is called in this paper unfairness $R L$.

Definition 6 (Unfairness RL). Given two pairs of distributions $\left(\boldsymbol{x}^{\star}, \boldsymbol{y}^{\star}\right),\left(\boldsymbol{x}^{\circ}, \boldsymbol{y}^{\circ}\right) \in \overline{\mathcal{P}}$ with means $\mu^{\star}=\mu\left(\boldsymbol{x}^{\star}\right)=\mu\left(\boldsymbol{y}^{\star}\right)$ and $\mu^{\circ}=\mu\left(\boldsymbol{x}^{\circ}\right)=\mu\left(\boldsymbol{y}^{\circ}\right)$, we will say that $\left(\boldsymbol{x}^{\star}, \boldsymbol{y}^{\star}\right)$ unfairness relative Lorenz dominates $\left(\boldsymbol{x}^{\circ}, \boldsymbol{y}^{\circ}\right)$, which we write $\left(\boldsymbol{x}^{\star}, \boldsymbol{y}^{\star}\right) \succeq_{U R L}\left(\boldsymbol{x}^{\circ}, \boldsymbol{y}^{\circ}\right)$, if and only if $\sum_{j=1}^{m} Q^{\star}\left(p_{j}\right) /\left(M \mu^{\star}\right) \geq \sum_{j=1}^{m} Q^{\circ}\left(p_{j}\right) /\left(M \mu^{\circ}\right)$ for all $m=1,2, \ldots, M$, where $Q\left(p_{j}\right)$ is the $j^{\text {th }}$ quantile mean of the distribution $\boldsymbol{z}:=\boldsymbol{x}-\boldsymbol{y}$.

As established by the authors, this criterion generalizes the traditional relative Lorenz approach, which consists in comparing two (actual) distributions $\boldsymbol{x}^{\star}$ and $\boldsymbol{x}^{\circ}$. Indeed, it can be easily shown that $\boldsymbol{x}^{\star} \succeq_{R L} \boldsymbol{x}^{\circ}$ if and only if $\left(\boldsymbol{x}^{\star}, \boldsymbol{\mu}\left(\boldsymbol{x}^{\star}\right)\right) \succeq_{U R L}\left(\boldsymbol{x}^{\circ}, \boldsymbol{\mu}\left(\boldsymbol{x}^{\circ}\right)\right)$.

\subsection{Indices of Inequality of Opportunity}

The indices introduced in this section evaluate the distance between the actual distribution $\boldsymbol{x}$ and the fair distribution $\boldsymbol{y}$. That is, an index is a measure which associates a real value $I(\boldsymbol{x}, \boldsymbol{y})$ 
to each pair of distributions $(\boldsymbol{x}, \boldsymbol{y}) \in \overline{\mathcal{P}}$. First of all, we define some properties that seem appropriate to capture the idea of distance mentioned above.

Non-Negativity. $\forall(\boldsymbol{x}, \boldsymbol{y}) \in \overline{\mathcal{P}}$, we have $I(\boldsymbol{x}, \boldsymbol{y}) \geq 0$.

IDENTity of Indiscernibles. $\forall(\boldsymbol{x}, \boldsymbol{y}) \in \overline{\mathcal{P}}, I(\boldsymbol{x}, \boldsymbol{y})=0$ if and only if $\boldsymbol{x}=\boldsymbol{y}$.

AnONymity. $\forall(\boldsymbol{x}, \boldsymbol{y}) \in \overline{\mathcal{P}}$, we have $I(\Pi \boldsymbol{x}, \Pi \boldsymbol{y})=I(\boldsymbol{x}, \boldsymbol{y})$ for all permutation matrices $\Pi$.

PRINCIPLE OF TRANSFERS. $\forall \boldsymbol{x}, \boldsymbol{x}^{\star} \in \Omega_{n}$, if $\boldsymbol{x}^{\star}$ is obtained from $\boldsymbol{x}$ by means of a progressive transfer, then we have $I(\boldsymbol{x}, \boldsymbol{\mu}) \geq I\left(\boldsymbol{x}^{\star}, \boldsymbol{\mu}\right)$, where $\boldsymbol{\mu}=\boldsymbol{\mu}(\boldsymbol{x})=\boldsymbol{\mu}\left(\boldsymbol{x}^{\star}\right)$.

SCAle Invariance. $\forall(\boldsymbol{x}, \boldsymbol{y}) \in \overline{\mathcal{P}}$, we have $I(\lambda \boldsymbol{x}, \lambda \boldsymbol{y})=I(\boldsymbol{x}, \boldsymbol{y})$ for all $\lambda \in \mathbb{R}_{+}$.

These properties are extensions of standard axioms in inequality measurement. We recall that for a distribution $\boldsymbol{x}$, an inequality index can be written as $I(\boldsymbol{x}, \boldsymbol{\mu}(\boldsymbol{x}))$. The first two properties require an index to return a null value when the actual distribution is exactly equivalent to the fair distribution, and a positive value otherwise. Anonymity means that the index is not affected by a permutation of the identity of the individuals. The principle of transfers states that a progressive transfer reduces the distance to the fair distribution, if this latter is egalitarian (the mean income of the actual distribution for all). Finally, according to scale invariance, a uniform scale transformation of all outcomes has no impact on the index.

In the literature some (classes of) indices exist which are consistent with these normative views. Almas et al. (2011) propose to use a slightly modified version of the Gini index. Considering $(\boldsymbol{x}, \boldsymbol{y}) \in \overline{\mathcal{P}}$ and $\boldsymbol{z}:=\boldsymbol{x}-\boldsymbol{y}$, the unfairness Gini is obtained by letting $I_{G}(\boldsymbol{x}, \boldsymbol{y})=G(\boldsymbol{z})$, where $G$ is defined in equation (3.1) but replacing $\mu(\boldsymbol{z})$ by $\mu=\mu(\boldsymbol{x})=\mu(\boldsymbol{y})$. Magdalou and Nock (2011) have characterized a large class of indices which satisfy the properties listed above. They have also justified the interest of such a class in evaluating unfairness in terms of opportunity. This class has already been presented in equations (3.2) and (3.3). Letting $\mu=\mu(\boldsymbol{x})=\mu(\boldsymbol{y})$, we have $I_{r}(\boldsymbol{x}, \boldsymbol{y})=D_{r}(\boldsymbol{x}, \boldsymbol{y}) /\left(n \mu^{r}\right)$. The parameter $r$ captures the inequality aversion of the decision maker. As $r$ decreases, the corresponding indices are more sensitive to a reduction in inequality of opportunity at the bottom of the actual distribution.

Other admissible classes exist in the literature. For instance, Devooght (2008) applies the measures of distributional change introduced by Cowell (1985). This family is equivalent to our class $I_{r}$ if and only if $r=1$. We have computed it in the empirical part of the paper. The rankings it provides - not presented here - are equivalent to those obtained using $I_{r}$. 


\section{Data and Descriptive Statistics}

\subsection{Data}

We use data provided by CEREQ (Centre d'Étude et de REcherche sur les Qualifications). CEREQ is a French institute which depends on the Ministry of National Education, the Ministry of the Economy, Finance and Industry, and the Ministry of Labour, Employment and Health. It mainly produces statistical series and quantitative studies on education, occupational integration and employment, at the regional and national levels. The data used are derived from two CEREQ longitudinal surveys called Generation, respectively for the years 1992 and 2004. This survey series initiated in the early 1990's is carried out every three years on a cohort of young people who had left the educational system three years before, whatever their level of education or their qualifications. ${ }^{13}$ It essentially investigates the first three years on the labour market of the considered new graduates. Samples of 27,000 and 65,000 individuals are, respectively, available in databases Generation 92 and Generation 04.

The dependent variable we use as a proxy for the educational outcomes is the (highest) level of training reached by the individual when she left higher education. It is referred to hereafter as "number of years of higher education". For example, if the number of years is equal to one, this means that the individual dropped out of higher education after the first academic year. We emphasize that it differs from the number of years spent in higher education: an individual who repeats the first academic year, for example, has a lower level of training than an individual enrolled in the second year. In the database, we have selected the individuals holding a baccalauréat (general or technological), which is the standard French secondary-school diploma for access to higher education.

The data are limited in two main respects. First, in the same level of training the data does not discriminate between successful and unsuccessful applicants for a particular academic degree. ${ }^{14}$ Hence, some of the individuals for whom the number of years of higher education is equal to zero, have not successfully completed upper secondary education (they have not passed the baccalauréat). Since our study is focused on higher education, only individuals with a number of years in higher education not lower than one, are considered (namely $4+$ ). This part of the database is called Gene-sup. ${ }^{15}$ Then, the number of years in higher education does not distinguish between more and less prestigious studies of the same length (this information is available but used as explanatory variable, as described below). Nevertheless, we assume that

\footnotetext{
${ }^{13}$ For example, the database Generation 04 was collected in 2007.

${ }^{14}$ The information is only available in database Generation 04 .

${ }^{15}$ With this data, unfortunately, we cannot investigate the question of equality of opportunity in the access to higher education, but only the question of equality of opportunity within higher education.
} 
the number of years in higher education is a suitable indicator of educational outcomes.

Among all the other variables which characterize an individual, we have retained those having a possible influence on school achievement. These variables and some descriptive statistics are listed in Table 2 (all the Tables and Figures are in the Appendix). Note that we have removed from the database all the individuals for whom missing data occurred. Finally 5,241 individuals for 1992 and 14,068 for 2004 remained in database. The dependent variable is characterized in 1992 and 2004 by two modal values, namely 2 and 5. These correspond to the number of years required to achieve the two most common French qualifications. For all the independent variables, the relative frequencies and the distribution among the possible values remained fairly stable between 1992 and 2004, despite the substantial increase in the number of individuals in the database. We note, however, that the majority of individuals were men in 1992, but women in 2004 .

Some details concerning the "parents' circumstances" variable are required. First, the socioprofessional category (SPC) of each parent - father and mother - was observed. We divided the SPC into three levels: favourable (executive, engineer, liberal profession, craftsman, entrepreneur), middle-class (teacher, technician, supervisor, salesman, middle-class job, farmer) and unfavourable (employee, worker, unemployed). The parents' circumstances variable takes the value favourable if and only if both parents have a favourable SPC. It takes the value unfavourable if and only if both parents have an unfavourable SPC. It takes the value middle-class in all other cases. Another admissible strategy could have been to keep the father's situation only. In the context of education, it has been established that the mother's SPC impacts school achievement, whereas the father's SPC determines the orientation (Boumahdi and Lemistre, 2007). Moreover, this influence depends on the gender of the individual. The father's SPC has a stronger effect on men, whereas the mother's SPC is more important for women.

The "Orientation post-secondary level" variable is grouped into three categories. First the selective studies, which refer to business schools, engineering schools and the so-called CPGE (a high-level training program to prepare for the previously mentioned schools). The unselective studies mainly correspond to University. Finally short studies deal with two-year graduation programs such as IUT, BTS and health studies.

\subsection{Descriptive Statistics and Compensation Scenarios}

On average, the mean number of years of higher education increased slightly from 2.98 in 1992 to 3.12 in 2004 . Whatever the decomposition (by parents' circumstances, by gender, etc.), the mean number of years in higher education increased to some extent for almost all the subgroups. Consequently, if the comparison between 1992 and 2004 only incorporates considerations for 
greater efficiency, the situation in 2004 seems better. Nevertheless, if we are concerned about inequality, the cross-tabulation of data with respect to the explanatory variables reveals some striking features.

One of the most important missions of the national education system - at the primary, secondary or higher levels - is to promote equality of opportunity for all individuals. As a consequence, school achievement should not be correlated to the parents' circumstances. But Table 2 reveals that this is clearly the case for higher education in France. Individuals who benefit from favourable parent's circumstances are, on average and in comparison with the leastfavoured individuals, characterized by an additional year of schooling. This feature increased slightly between 1992 and 2004: from 2.64 to 3.59 in 1992, and from 2.79 to 3.83 in 2004. The situation is almost equivalent if we focus on the gender, women being less educated than men. Here again, the gap tends to be larger in 2004. This result appears to confirm that the social origin of an individual impacts her school achievement.

Whereas the two variables considered above, parents and gender, are undoubtedly a matter of circumstances, it is less obvious for the others: the secondary school entrance level, the baccalauréat obtained and the chosen orientation after secondary school. Thus the inequalities found in this respect cannot be described, without discussion, as fair or unfair. Therefore the cross-tabulation with respect to these variables is not detailed here. We just mention that individuals with grade skipping at the entrance to secondary school, holding a baccalauréat in science and having completed a selective degree course, are on average better educated than other individuals.

Finally, we propose different scenarios to investigate the cut between efforts and circumstances. In Table 1, the scenarios are ordered from the most libertarian to the most egalitarian views on justice. We assume that inequality arising from differences in parents' circumstances is

Table 1: Compensation scenarios

\begin{tabular}{|c|c|c|}
\hline Scenarios & Circumstances & Efforts \\
\hline S1 & Parents' Circ. & Gender / Second. / Bac. / Orient. / Others \\
\hline $\mathrm{S} 2$ & Parents' Circ. / Gender & Second. / Bac. / Orient. / Others \\
\hline S3 & Parents' Circ. / Gender / Second. & Bac. / Orient. / Others \\
\hline $\mathrm{S} 4$ & Parents' Circ. / Gender / Second. / Bac. & Orient. / Others \\
\hline S5 & Parents' Circ. / Gender / Second. / Bac. / Orient. & Others \\
\hline S6 & Parents' Circ. / Gender / Second. / Bac. / Orient. / Others & - \\
\hline
\end{tabular}

the most offensive. Hence, even for the most libertarian criteria applied in the following, a necessary condition to achieve equality of opportunity is that differences in parents' circumstances have no effect on school achievement. In the last scenario (S6), all the inequalities have to be compensated for. This is the view captured by the standard inequality criteria. 


\section{Opportunities in French Higher Education}

Even if it falls outside the scope of the paper, we start this Section by a brief overview of inequality in the standard sense. We specify that for all our quasi-orderings, we have computed the decile means (letting $M=10$ ) and implemented statistical inference (significance level at $5 \%$ ) using the intersection-union method as detailed in Magdalou and Moyes (2012). First, the quantile functions for 1992 and 2004 are presented in Figure 1 (Appendix). Despite the fact that, on average, the number of years of higher education was slightly higher in 2004, we cannot say that 2004 is characterized by greater efficiency. We observe that, at the bottom of the distributions, the curve was higher in 1992. Thus the situation for less-educated individuals - approximatively the first $18 \%$ - was better in 1992. The situation is reversed at the top of the distributions, and almost equivalent anywhere else. Hence, the situtation has worsened for less-educated individuals, but improved for the better educated.

This pattern explains the significant increase in inequality between 1992 and 2004 in the sense of the relative Lorenz curves $\left(\boldsymbol{x}^{1992} \succeq_{R L} \boldsymbol{x}^{2004}\right)$, as shown in Figure 1. The Gini index and the generalized entropies, with different values for the inequality aversion parameter as presented in Table 3, support this result: inequality was higher in 2004 than in 1992. Even if the descriptive statistics presented in the previous subsection tend to establish a relation with the circumstances, we cannot conclude at this stage that this inequality is unfair.

\subsection{Results by the Categorial Approach}

In this subsection, we investigate equality of opportunity according to the categorial approach. Among all the compensation scenarios described in Table 1, we have chosen to focus the discussion on the most libertarian, namely S1, where only the parents' circumstances have to be compensated for. For each year, we distinguish and compare the quantile functions for all three types: favourable, middle-class and unfavourable parents' circumstances. Each function can be written as the line of a matrix, as proposed in equation (4.1). We obtained the matrices, one per year, presented in Table 4.

The pattern of the quantile functions illustrated in Figure 2, is unambiguous: whatever the year - 1992 or 2004 - educational opportunities are greater for individuals with favourable parents' circumstances, as compared to middle-class individuals, and middle-class individuals benefit from better opportunities than the least-favoured ones. In the sense of Definition 2, there is strict inequality of opportunity within the distribution both in 1992 and in 2004 . We note that the hierarchy of the three types between the distributions, taken by pairs, is significant for each year. 
Yet was the situation better in 1992 or 2004? If we compare the quantile functions for each type between 1992 and 2004, as illustrated in Figure 3, the result is equivalent to that observed for the global distributions: the situation has worsened for the less-educated individuals and improved for the better-educated ones. A striking feature related to Figure 3 has to be mentioned. First, between 1992 and 2004, the deterioration of the situation for the less-educated individuals can be ranked as follows: the greatest for the least-favoured individuals, slightly less for the middle-class, and much less for the most-favoured individuals. The scheme is exactly the opposite for the best-educated: the improvement is all the greater as the parents' circumstances improve. Nevertheless, this result - which tends to corroborate the fact that the impact of the parents' circumstances on the educational outcome increased from 1992 to 2004 - is less clear in the middle of the distributions. From the $20 \%$ to the $85 \%$ less-educated individuals in each group, the situation was equal or somewhere greater in 2004 than in 1992 for individuals with unfavourable parents' circumstances, whereas the pattern is reversed for the two other groups (most-favoured and middle-class).

We now compare 1992 and 2004 according to within-effort opportunity. In the two matrices presented in Table 4, each column represents a particular level of effort. The higher the rank in the quantile function, the greater the effort. The criterion $\succeq_{E R L}$ compares the columns of each year, one-to-one, according to the standard criterion $\succeq_{R L}$. As illustrated in Figure 4, the situation is almost equivalent for all levels of effort, apart from D2 and D7. For one of the lowest levels of effort (D2), the situation was better in 1992, but the opposite is observed for one of the highest efforts (D7). Here, in terms of inequality of opportunity $\left(\boldsymbol{x}^{1992} \#_{E R L} \boldsymbol{x}^{2004}\right)$, we cannot establishs the dominance of one distribution.

The between-type opportunity evaluation requires an ordering according to the circumstances, on the basis of the mean outcomes which characterize each type. This ordering exists for our three types, recalling that they are differentiated according to the parents' circumstances (see Table 2). The criterion $\succeq_{T R L}$ compares the relative Lorenz curves, computed on the mean outcomes by type. The inference test results in an equivalence between 1992 and 2004 $\left(\boldsymbol{x}^{1992} \sim_{T R L} \boldsymbol{x}^{2004}\right)$. Here again, even if inequality was significantly higher in 2004 than in 1992, we cannot say that inequality of opportunity was higher in 2004.

After discussing the dominance criteria following successively the within-effort and betweentype approaches, we now present the results for the generalized entropy class of indices, as measures of inequality of opportunity. With usual values for the inequality parameter, we first see from the columns All in Table 5 that global inequality increased between 1992 and 2004, as stated in Section 6. We now isolate the share of inequality due to (parents') circumstances, in the sense of the within-effort approach. Whereas the inequality due to effort was significantly higher in 2004, inequality due to circumstances decreased for almost all values of the aversion 
parameter presented in Table 5. This represented more or less $14 \%$ in 1992 and $9 \%$ in 2004 . The same observation applies to the decomposition according to the between-type approach. As compared to the previous one, this approach underweights the share of inequality due to circumstances which now represents, more or less, $6 \%$ in 1992 and $4 \%$ in 2004.

Unfortunately, these last results are not robust. When the value of the aversion parameter is close to 0 - it is between -2 and 2 in Table 5 - the index is mainly concerned by inequality in the middle of the distributions. As the parameter decreases [resp. increases], the index is more sensitive to inequality in the bottom [resp. top] of the distributions. As illustrated in Figure 6, inequality due to circumstances was higher in 2004 for all the parameters weaker than -1.5 or higher than 3 according to the within-effort approach, and higher than 4 according to the between-type approach. This corroborates the results presented in the third paragraph of this Section.

As a main conclusion, the categorial approach cannot provide an unambiguous ranking in terms of inequality of opportunity, between 1992 and 2004. The only conclusive criterion leads to equivalence, whereas all the others cannot discriminate in a robust way between the distributions. Nevertheless a clear pattern appears. Between 1992 and 2004, the situation worsened for the less-educated individuals, and deeply for the least-favoured individuals. On the other hand the situation improved for better-educated individuals, and the improvement was greater as the parents' circumstances increased. However, in the middle of the distribution, whereas the overall situation was stable between 1992 and 2004, it improved for the least-favoured individuals and slightly deteriorated for the others. Hence, inequality of opportunity tends to decrease in the middle of the distribution but increase at the two extremes (the bottom and the top of the distribution).

\subsection{Results by the Counterfactual Approach}

The counterfactual approach requires information about the influence on school achievement of the effort and circumstance variables. More precisely, it is assumed that a functional dependence exists between the number of years of higher education variable and all the other effort and/or circumstance variables, such that $x_{i}=x\left(\boldsymbol{a}_{i}\right)$ where $\boldsymbol{a}_{i}:=\left(\boldsymbol{e}_{i} ; \boldsymbol{c}_{i}\right)$. The first step consists in providing an empirical estimation of the dependence. We chose a loglinear model: ${ }^{16}$

$$
\log x\left(\boldsymbol{a}_{i}\right)=\left(\beta_{1} e_{i}^{1}+\beta_{2} e_{i}^{2}+\cdots+\beta_{E} e_{i}^{E}\right)+\left(\alpha_{1} c_{i}^{1}+\alpha_{2} c_{i}^{2}+\cdots+\alpha_{C} c_{i}^{C}\right)+\epsilon_{i}, \quad \epsilon_{i} \sim N(0,1),
$$

${ }^{16}$ We tested some other estimation methods. One of the best known models, proposed by Bourguignon et al. (2007), assumes that efforts are affected by circumstances. The quality of the regression appears very poor in our context, which is why it was not adopted. Then, the Box-Cox test tends to favour the loglinear estimation, as chosen in the present paper, rather than a linear one. 
where $\boldsymbol{\beta}:=\left(\beta_{1}, \beta_{2}, \ldots, \beta_{E}\right)$ and $\boldsymbol{\alpha}:=\left(\alpha_{1}, \alpha_{2}, \ldots, \alpha_{C}\right)$ are the parameter vectors of the regression. According to responsibility ethics, equality of opportunity is attained if and only if $\boldsymbol{\alpha}:=(0,0, \ldots, 0)$, in which circumstances do no affect the level of education.

Table 6 shows the regression results for 1992 and 2004. Note that dummies have been introduced for each explanatory variable. In order to compute the fair distribution as indicated in equation (5.1), we chose as a reference the least favourable profile: unfavourable parents' circumstances (where both parents are characterized by an unfavourable SPC), woman, entrance in secondary school with delay, no general baccalauréat (others), and short/professional orientation in higher education.

The first observation is the low (adjusted) R-squared - around 0.25 - whatever the year which questions the robustness of the estimations. None the less the regressions are acceptable with regard to Fisher's test. Some other variables which have an explanatory power on our dependent variable (see Jaoul-Grammare and Nakhili, 2010) are available in the database for 2004 but not for 1992 (for example place of residence, having or not obtained distinctions in secondary school examinations, having or not a professional project when entering higher education). For consistency reasons, the same variables were considered in both investigations.

The main finding was the positive and significant impact in both regressions of almost all the explanatory variables. The influence of the parents' circumstances is stronger in 2004. In 1992, the fact of having a father in the middle-class or a mother with a favourable SPC - as compared to an individual for whom both parents had an unfavourable SPC - did not significantly increase the number of years of higher education (at a $5 \%$ significance level). This impact was significant in 2004. Thus the gap between the individuals with unfavourable parents' circumstances and the others tended to increase from 1992 to 2004. The influence of gender, here again, was significant for the both years but higher in 2004. Hence the level of higher education increased faster for men, a result which corrobates the descriptive statistics in Table 2. All the other variables had a positive and significative impact, comparable for both years, apart for entrance without delay but without grade skipping (normal). The impact of this variable was not significant.

We are now ready to present the measures of inequality of opportunity, according to the counterfactual approach. The first step deals with the responsibility cut. We recall that the different scenarios were stated in Table 1, and ordered from the most libertarian to the most egalitarian. As emphasized by Devooght (2008), the most difficult problem is the treatment of the unobservable factors, captured by the error term. As presented in Table 1, these factors were incorporated into the efforts. Thus, a rather libertarian view on responsibility ethics is embraced in all the scenarios, adopting, each time, a minimal compensation approach. ${ }^{17}$

${ }^{17}$ We illustrate the computation of $y_{i}(\boldsymbol{a})$ in (5.1) for scenario S1, where vector $\boldsymbol{c}_{i}$ is limited to the parents' circumstances. Since dummies have be introduced, let $c_{i}^{k, l}$ be a list of binary variables $(0$ or 1$)$, where $k=F, M$ 
In the following, the discussion focuses on scenario S1, where only the parents' circumstances have to be compensated for (the others lead to equivalent findings). Figure 7 shows the relative Lorenz curves, for each year, of the actual outcome distributions and the reference distributions. In the latter, the inequality of opportunity due to circumstances has been eliminated (the reference distribution can be seen as a fair distribution). We observe that the reference distribution was slightly less egalitarian in 2004. This observation corroborates the result presented in Table 5 (categorial approach) indicating a significant increase in the inequality due to responsibility - more specifically, due to factors that do not fall directly within the parents' circumstances. Figure 7 also presents the unfairness Lorenz curves for 1992 and 2004. The curve in 1992 is everywhere not significantly below the curve in 2004, but significantly above at some points, which means that inequality of opportunity was higher in 2004 . Whatever the scenario, from S1 to S5, the pattern remains the same: an increase in unfair inequality.

Considering now indices $I_{G}$ and $I_{r}$ as measures of inequality of opportunity (see Section 5), we obtain here again the same clear-cut result. Table 7 centralizes the values of each index in the different scenarios, with different values of the aversion parameter $r$ for $I_{r}$. The results for scenario S6 have been already presented in Table 3. We recall that, if all the inequalities are described as unfair, indices $I_{G}$ and $I_{r}$ come down, respectively, to the standard Gini index and the generalized entropies. Whatever the scenario (from the most libertarian to the most egalitarian) and whatever the index, we observe in Table 7 that the inequality of opportunity increased from 1992 to 2004 . Unlike the results obtained for the indices in the categorial approach, this finding is robust to a change in parameters.

\section{Discussion}

A recent OECD report (OECD, 2009) establishes that France is one of the countries where the influence of the social background on school achievement is the greatest. Even if access to education seems to be easier today for children with unfavourable parents' circumstances, the final level of education remains correlated to social background (Crahay, 2000; Thelot and Vallet, 2000; Nakhili, 2005; Jaoul-Grammare, 2007; Beaud, 2008). It is now considered that inequalities have not been eliminated, but have only shifted to higher university degrees (Prost, 1986).

(F="father", $\mathrm{M}=$ "mother") and $l=F, M, U$ (F="favourable SPC", $\mathrm{M}=$ "middle-class SPC", $\mathrm{U}=$ "unfavourable SPC"). As described in Section 6.2, an individual $i$ has unfavourable parents' circumstances if and only if $c_{i}^{F, U}=c_{i}^{M, U}=1$. In scenario S1, all the other explanatory variables are assumed to be components of $\boldsymbol{e}_{i}$ (also treated as dummies). After estimating the parameters $\boldsymbol{\beta}$ and $\boldsymbol{\alpha}$, we obtain $x\left(\overline{\boldsymbol{e}}, \boldsymbol{c}_{i}\right)$ be replacing the true vector $\boldsymbol{e}_{i}$ by the reference $\overline{\boldsymbol{e}}$, as described at the beginning of this Section. We take the value 0 as reference for the error term $\epsilon_{i}$ in (7.1), recalling that it is treated as an effort (hence a variable in $\boldsymbol{e}_{i}$ ). 
Our descriptive statistics and regression models provide results in the same direction. First, on average, the level of education has increased for almost all the categories of individuals (favourable or unfavourable parents' circumstances, women or men, ...), but the evolution significantly differs between categories and within each category. Between categories, it appears that the individuals with the most-favourable circumstances are the main beneficiaries. As a main finding, the impact of parents' circumstances and gender on the educational outcome increased between 1992 and 2004. Within each category, the situation worsened in 2004 for lesseducated individuals, whereas there was a significant improvement for the better-educated ones. This detrimental effect was exacerbated for individuals with the least-favourable circumstances.

In order to assess the magnitude and the evolution of inequality of opportunity in higher education in France between 1992 and 2004, we proposed a two-level classification of the measures introduced in the literature, distinguishing between the categorial and the counterfactual approaches. The first uncontroversial and expected result was the existence of inequality of opportunity related to parents' circumstances (1992 and 2004). The comparison of the two years led to a more contrasted pattern. The categorial approach assumes the existence of categories of persons sharing common characteristics. If the individuals are brought in three groups according to parents' circumstances, it can be observed that inequality of opportunity increased between 1992 and 2004 for the less-educated and the best-educated individuals, but tended to decrease in the middle of the distribution. The main drawback of the categorial approach is that the information available for each individual is not fully exploited, and the circumstances have to be limited to a small number of dimensions (here, parents' circumstances only). The counterfactual approach has the advantage of analyzing the situation of individuals independently from each other, defining what a fair outcome could be for anyone. Whatever the compensation scenario we considered (from the most egalitarian to the most libertarian), the counterfactual approach always concludes that the situation, in terms of equality of opportunity, was better in 1992 .

To sum up, an overview of our results suggests that inequality of opportunity in the French higher education system tended to increase during the reporting period. A recent structural reform of the higher education system in France, started during the Sarkozy presidency (20072012), is the increasing autonomy of the universities. The declared objectives were essentially excellence, competitiveness and equal opportunities. With regard to the latter point, the university was also described by the reform as a means to promote upward social mobility. Of course, the time perspective is not yet sufficient to ensure that the targets are met. We hope that the tools presented in this paper will enable us to monitor in the coming years the evolution of such education systems in terms of opportunities. 


\section{References}

Almas, I., Cappelen, A., Lind, J., Sørensen, E. and Tungodden, B. (2011). Measuring unfair (in)equality. Journal of Public Economics, 95, 588-499.

Arneson, R. (1989). Equality and equal opportunity for welfare. Philosophical Studies, 56, $77-93$.

- (1990). Liberalism, distributive subjectivism, and equal opportunity for welfare. Philosophy and Public Affairs, 19, 158-194.

Beach, C., Chow, K., Formby, J. and Slotsve, G. (1994). Statistical inference for decile means. Economics Letters, 45, 161-167.

BeAud, S. (2008). Enseignement supérieur: la "démocratisation scolaire" en panne. Formation Emploi, 1, 149-165.

Bossert, W. (1995). Redistribution mechanisms based on individual characteristics. Mathematical Social Sciences, 29, 1-17.

- and Fleurbaey, M. (1996). Redistribution and compensation. Social Choice and Welfare, 13, 343-355.

Boumahdi, R. and Lemistre, P. (2007). Devenir cadre : une affaire de famille, de genre ou d'éducation? Revue d'Économie Appliquée, 2, 123-156.

Bourguignon, F., Ferreira, H. and Ménendez, M. (2007). Inequality of opportunity in Brazil. Review of Income and Wealth, 53, 585-618.

Brunello, G. and Checchi, D. (2007). Does school tracking affect equality of opportunity? new international evidence. Economic Policy, 22, 781-861.

Carneiro, P. (2008). Inequality of opportunity and inequality in education achievement in Portugal. Portuguese Economic Journal, 7, 17-41.

Checchi, D. and Peragine, V. (2010). Inequality of opportunity in Italy. Journal of Economic Inequality, 8, 429-450.

Cohen, G. (1989). On the currency of egalitarian justice. Ethics, 99, 906-944.

Cowell, F. (1985). Measures of distributional change: An axiomatic approach. Review on Economic Studies, 52, 135-151.

Crahay, M. (2000). L'école peut-elle être efficace? Bruxelles: De Boeck.

De Villé, P. (2003). Equal opportunity in the educational system and the ethics of responsibility, Cahier de Recherche 17, GIRSEF, Louvain-la-Neuve.

Devooght, K. (2008). To each the same and to each his own: A proposal to measure responsibility-sensitive income inequality. Economica, 75, 280-295.

Dworkin, S. (1981a). What is inequality? part 1: Equality of welfare. Philosophy and Public Affairs, 10, 185-246.

- (1981b). What is inequality? part 2: Equality of resources. Philosophy and Public Affairs, 
10, 283-345.

Fleurbaey, M. (1994). On fair compensation. Theory and Decision, 36, 277-307.

- (1995a). Equality and responsibility. European Economic Review, 39, 683-689.

- (1995b). The requisites of equal opportunity. In W. A. Barnett (ed.), Social Choice, Welfare, Ethics, Cambridge: Cambridge University Press, pp. 37-53.

- (1995c). Three solutions for the compensation problem. Journal of Economic Theory, 65, $506-521$.

- (2008). Fairness, Responsability and Welfare. Oxford: Oxford University Press.

Foster, J. and Shneyerov, A. (2000). Path independent inequality measures. Journal of Economic Theory, 91, 199-222.

Gastwirth, J. (1971). A general definition of the Lorenz curve. Econometrica, 39, 1037-1039.

Heineck, G. and Riphahn, R. (2009). Intergenerational transmission of educational attainment in Germany: The last five decades. Journal of Economics and Statistics, 229, 36-60.

JaOul-Grammare, M. (2007). Social attributes, equity and higher educative path. microeconometric study of a discrete choice model with logistic regression. Applied Economics Letters, 14, 287-291.

- and NAKHILI, N. (2010). Quels facteurs influencent les poursuites d'études dans l'enseignement supérieur?, Net.Doc 68, CEREQ Publications.

Kolm, S. (1996). Modern Theories of Justice. Cambridge: MIT Press.

Lefranc, A., Pistolesi, N. and Trannoy, A. (2009). Equality of opportunity and luck: Definitions and testables conditions, with an application to income in France. Journal of Public Economics, 93, 1189-1207.

Machin, S. and Vignoles, A. (2004). Educational inequality: The widening socio-economic gap. Fiscal Policies, 25, 107-128.

Magdalou, B. and Moyes, P. (2012). The absence of deprivation as a measure of social well-being: An empirical investigation. Economics Letters, 116, 75-79.

- and Nock, R. (2011). Income distributions and decomposable divergence measures. Journal of Economic Theory, 146, 2440-2454.

NAKHILI, N. (2005). Impact du contexte scolaire dans l'élaboration des choix d'études supérieures des élèves de terminale. Education et Formations, 72, 155-167.

Ooghe, E. (2010). Partial compensation/responsability, Center for Economic Studies Discussion Paper 10.21, KULeuven.

-, Schokkaert, E. and VAn De GAer, D. (2007). Equality of opportunity versus equality of opportunity sets. Social Choice and Welfare, 28, 209-230.

Peragine, V. (2004). Measuring and implementing equity of opportunity for income. Social Choice and Welfare, 22, 187-210.

— and SerlengA, L. (2008). Higher education and equality of opportunity in Italy. In J. Bishop 
and B. Zheng (eds.), Research in Economic Inequality, vol. 14, Emerald Group Publishing Limited.

Prost, A. (1986). L'enseignement supérieur s'est-il démocratisé ?Les élèves des lycées et collèges de l'agglomération d'Orléans de 1945 á 1980. Paris: Presse Universitaire de France.

RAmos, X. and VAN DE GAER, D. (2012). Empirical approaches to inequality of opportunity: Principles, measures and evidence, IZA Discussion Paper Series, No. 6672.

Rawls, J. (1971). A Theory of Justice. Cambridge: Harvard University Press.

Roemer, J. (1993). A pragmatic theory of responsability for the egalitarian planner. Philosophy and Public Affairs, 22, 146-166.

- (1998). Equality of Opportunity. Cambridge: Harvard University Press.

Schutz, G., Ursprung, H. and Woessmann, L. (2008). Education policy and equality of opportunity. Kyklos, 61, 279-308.

Sen, A. (1985). Commodities and Capabilities. Amsterdam: North-Holland.

Thelot, C. and Vallet, L.-A. (2000). La réduction des inégalités sociales devant l'école depuis le début du siècle. Économie et Statistiques, 334, 4-32.

VAN DE GAER, D. (1993). Equality of Opportunity and Investments in Human Capital. Ph.D Thesis, KULeuven.

Waltenberg, F. and Vandenberghe, V. (2007). What does it take to achieve equality of opportunity in education? an empirical investigation based on brazilian data. Economics of Education Review, 26, 709-723. 


\section{A. Appendix}

Table 2: Variables and descriptive statistics

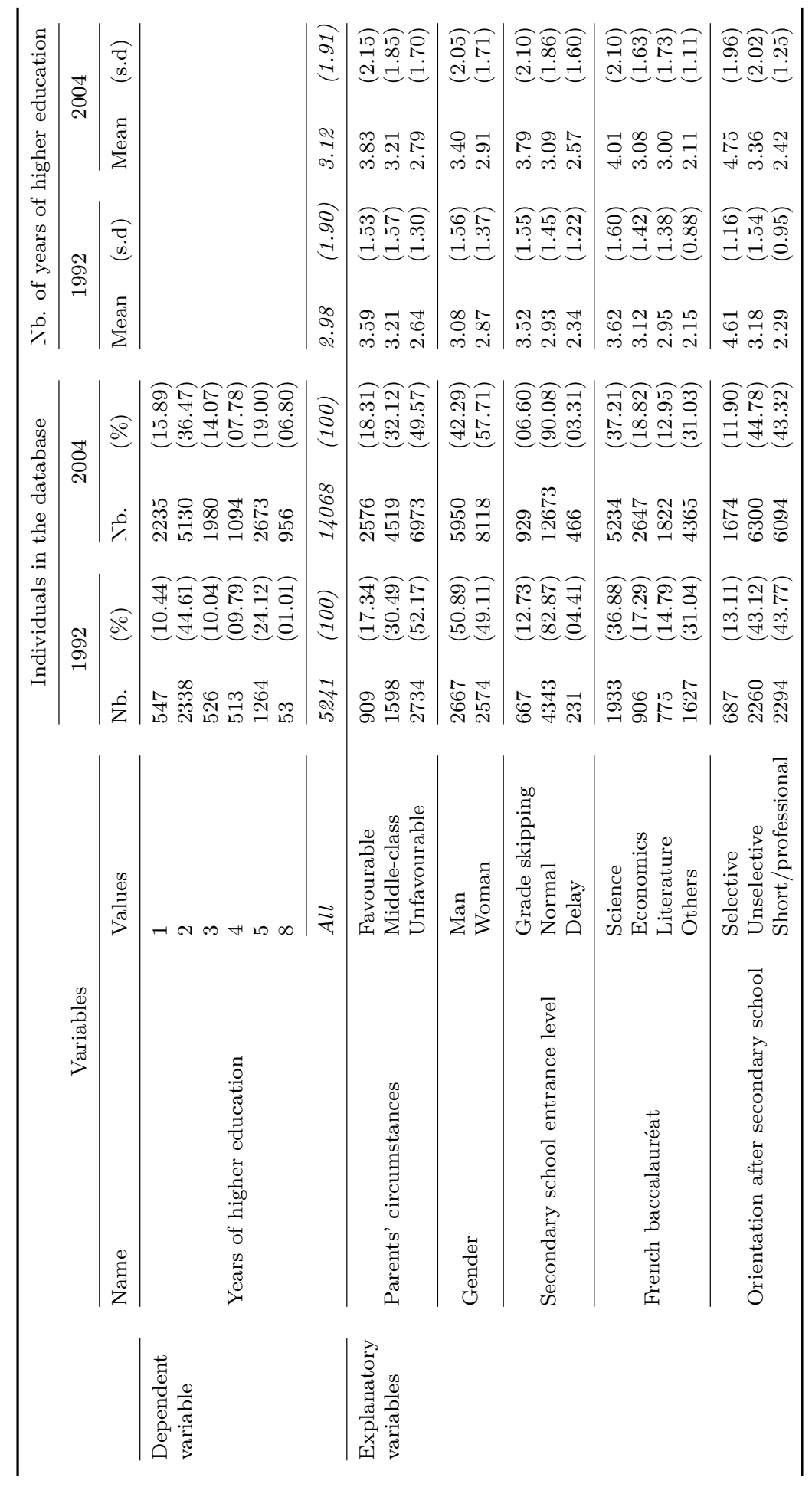


Figure 1: Quantile functions and relative Lorenz curves $\left(\succeq_{R L}\right)$
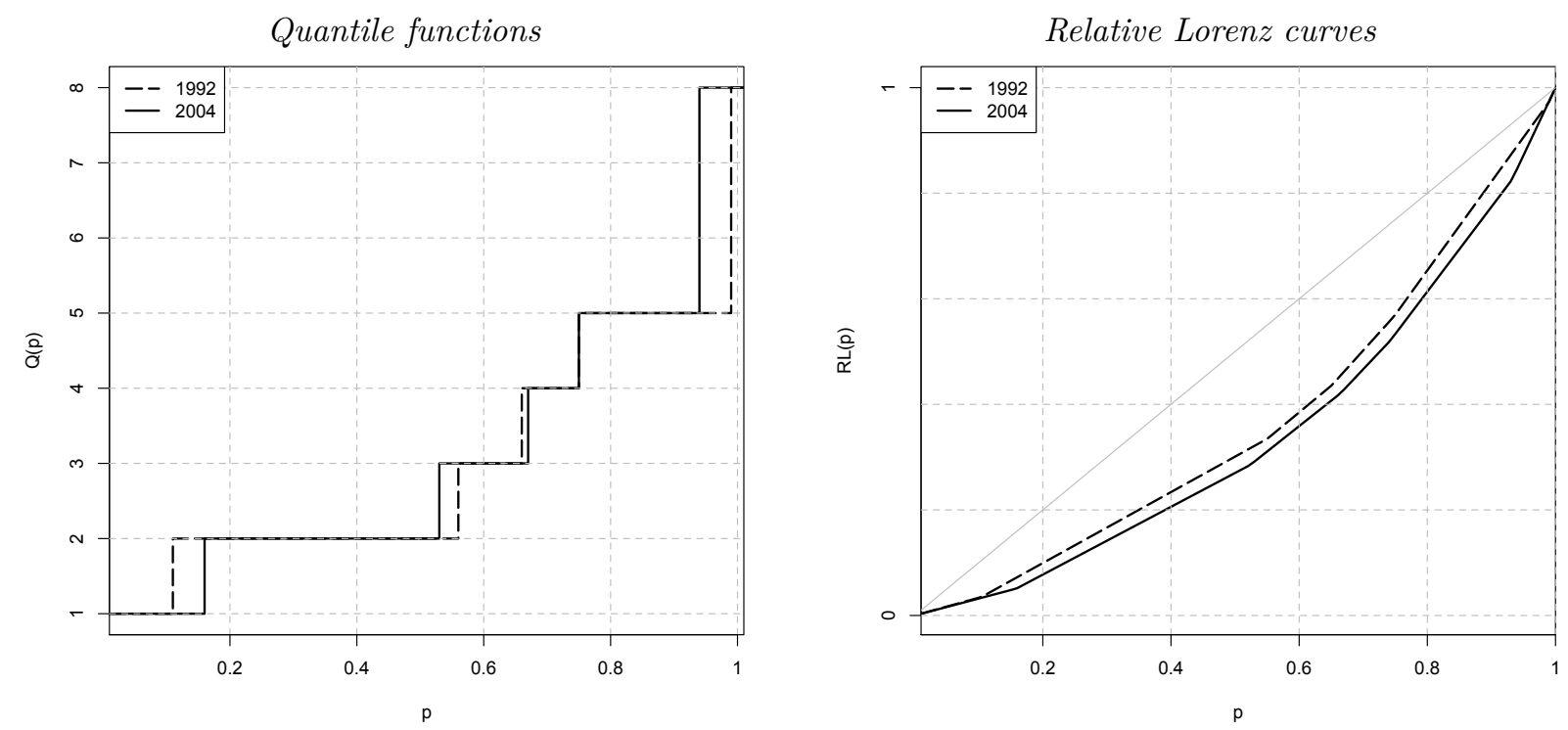

Table 3: Standard inequality indices

\begin{tabular}{ccccc}
\hline Indices & & 1992 & 2004 & Difference \\
\cline { 1 - 1 } \cline { 5 - 6 } Gini & & 0.2642 & 0.3170 & 0.0528 \\
Gen. Entropy $(r=-2)$ & & 0.1892 & 0.2830 & 0.0938 \\
Gen. Entropy $(r=-1)$ & 0.1456 & 0.2061 & 0.0605 \\
Gen. Entropy $(r=0)$ & 0.1253 & 0.1731 & 0.0478 \\
Gen. Entropy $(r=1)$ & 0.1185 & 0.1661 & 0.0476 \\
Gen. Entropy $(r=2)$ & 0.1216 & 0.1801 & 0.0585 \\
\hline
\end{tabular}

Table 4: Matrices of decile means, conditional on parents' circumstances

\begin{tabular}{|c|c|c|c|c|c|c|c|c|c|c|c|}
\hline \multirow[b]{2}{*}{ Year } & \multirow[b]{2}{*}{ Parents' circumstances } & \multicolumn{10}{|c|}{ Decile means (quantiles means with $\mathrm{M}=10$ ) } \\
\hline & & D1 & $\mathrm{D} 2$ & D3 & $\mathrm{D} 4$ & D5 & D6 & D7 & D8 & D9 & $\overline{\mathrm{D} 10}$ \\
\hline \multirow{3}{*}{1992} & Favourable & 1.21 & 2.00 & 2.00 & 2.45 & 3.57 & 4.30 & 5.00 & 5.00 & 5.00 & 5.33 \\
\hline & Middle-Class & 1.02 & 2.00 & 2.00 & 2.00 & 2.16 & 3.20 & 4.22 & 5.00 & 5.00 & 5.51 \\
\hline & Unfavourable & 1.00 & 1.83 & 2.00 & 2.00 & 2.00 & 2.00 & 2.46 & 3.39 & 4.50 & 5.18 \\
\hline \multirow{3}{*}{2004} & Favourable & 1.00 & 1.80 & 2.00 & 2.34 & 3.00 & 4.06 & 5.00 & 5.00 & 6.06 & 8.00 \\
\hline & Middle-Class & 1.00 & 1.53 & 2.00 & 2.00 & 2.16 & 3.00 & 3.69 & 4.83 & 5.00 & 6.92 \\
\hline & Unfavourable & 1.00 & 1.19 & 2.00 & 2.00 & 2.00 & 2.00 & 2.92 & 3.54 & 4.86 & 6.37 \\
\hline
\end{tabular}


Figure 2: Quantile functions, conditional on parents' circumstances
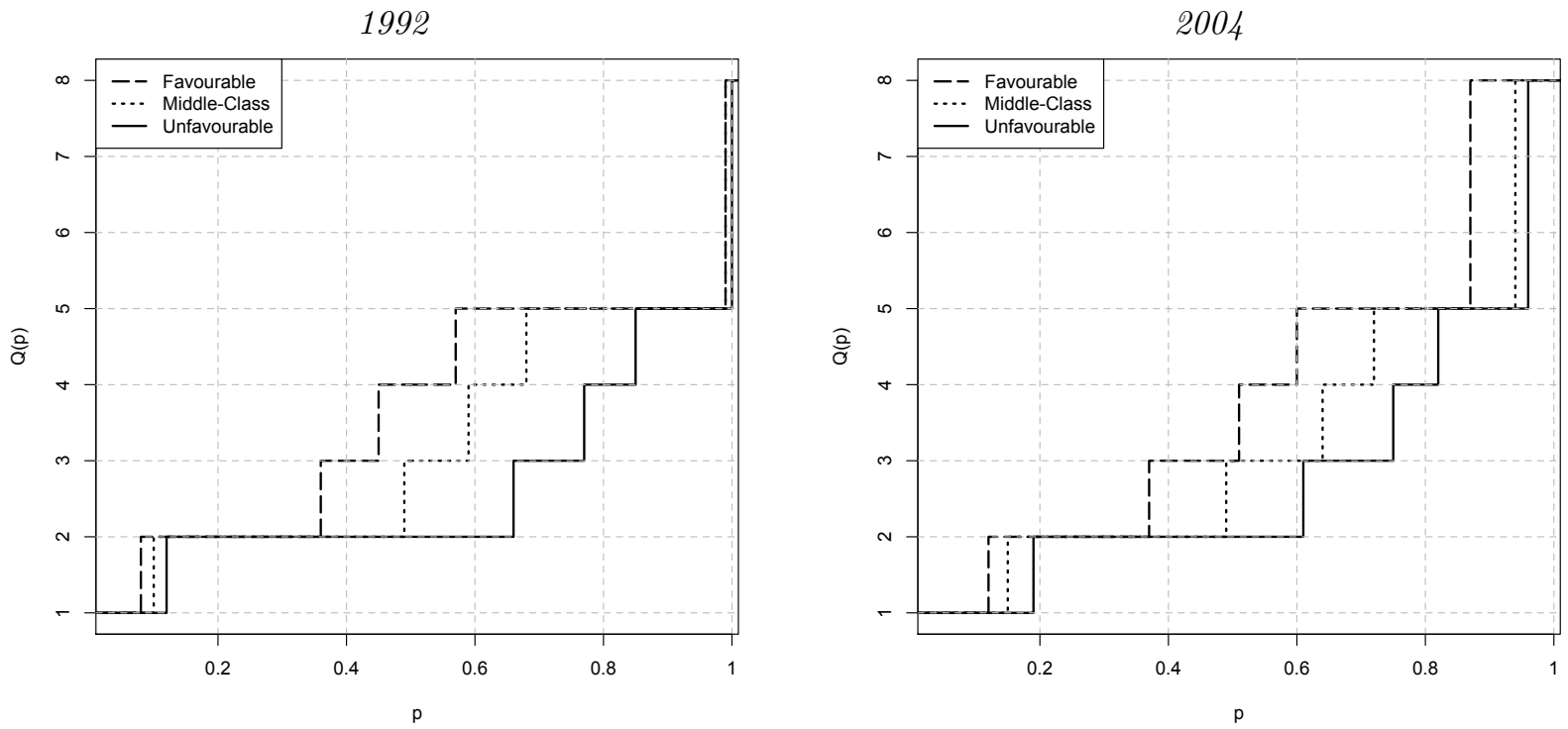

Table 5: Generalized entropy decomposition fair/unfair inequality

\begin{tabular}{|c|c|c|c|c|c|c|c|c|c|c|}
\hline \multirow{3}{*}{ Param. $r$} & \multicolumn{4}{|c|}{ Within-Effort Opportunity Dec. } & \multicolumn{4}{|c|}{ Between-Type Opportunity Dec. } & \multirow{2}{*}{\multicolumn{2}{|c|}{ All }} \\
\hline & \multicolumn{2}{|c|}{ Responsibility } & \multicolumn{2}{|c|}{ Circumstances } & \multicolumn{2}{|c|}{ Responsibility } & \multicolumn{2}{|c|}{ Circumstances } & & \\
\hline & 1992 & 2004 & 1992 & 2004 & 1992 & 2004 & 1992 & 2004 & 1992 & 2004 \\
\hline-2 & $\begin{array}{c}0.1650 \\
(87.24 \%)\end{array}$ & $\begin{array}{c}0.2556 \\
(90.31 \%)\end{array}$ & $\begin{array}{c}0.0241 \\
(12.76 \%)\end{array}$ & $\begin{array}{c}0.0274 \\
(09.69 \%)\end{array}$ & $\begin{array}{c}0.1815 \\
(95.92 \%)\end{array}$ & $\begin{array}{c}0.2761 \\
(97.54 \%)\end{array}$ & $\begin{array}{c}0.0077 \\
(04.08 \%)\end{array}$ & $\begin{array}{c}0.0070 \\
(02.46 \%)\end{array}$ & $\begin{array}{c}0.1892 \\
(100 \%)\end{array}$ & $\begin{array}{l}0.2830 \\
(100 \%)\end{array}$ \\
\hline-1 & $\begin{array}{c}0.1262 \\
(86.65 \%)\end{array}$ & $\begin{array}{c}0.1883 \\
(91.32 \%)\end{array}$ & $\begin{array}{c}0.0194 \\
(13.35 \%)\end{array}$ & $\begin{array}{c}0.0179 \\
(08.68 \%)\end{array}$ & $\begin{array}{c}0.1378 \\
(94.68 \%)\end{array}$ & $\begin{array}{c}0.1990 \\
(96.56 \%)\end{array}$ & $\begin{array}{c}0.0078 \\
(05.33 \%)\end{array}$ & $\begin{array}{c}0.0071 \\
(03.44 \%)\end{array}$ & $\begin{array}{l}0.1456 \\
(100 \%)\end{array}$ & $\begin{array}{l}0.2061 \\
(100 \%)\end{array}$ \\
\hline 0 & $\begin{array}{c}0.1076 \\
(85.87 \%)\end{array}$ & $\begin{array}{c}0.1587 \\
(91.69 \%)\end{array}$ & $\begin{array}{c}0.0177 \\
(14.13 \%)\end{array}$ & $\begin{array}{c}0.0144 \\
(08.31 \%)\end{array}$ & $\begin{array}{c}0.1175 \\
(93.77 \%)\end{array}$ & $\begin{array}{c}0.1659 \\
(95.81 \%)\end{array}$ & $\begin{array}{c}0.0078 \\
(06.23 \%)\end{array}$ & $\begin{array}{c}0.0073 \\
(04.19 \%)\end{array}$ & $\begin{array}{l}0.1253 \\
(100 \%)\end{array}$ & $\begin{array}{l}0.1731 \\
(100 \%)\end{array}$ \\
\hline 1 & $\begin{array}{c}0.1007 \\
(84.98 \%)\end{array}$ & $\begin{array}{c}0.1518 \\
(91.37 \%)\end{array}$ & $\begin{array}{c}0.0178 \\
(15.02 \%)\end{array}$ & $\begin{array}{c}0.0143 \\
(08.63 \%)\end{array}$ & $\begin{array}{c}0.1106 \\
(93.34 \%)\end{array}$ & $\begin{array}{c}0.1587 \\
(95.52 \%)\end{array}$ & $\begin{array}{c}0.0079 \\
(06.66 \%)\end{array}$ & $\begin{array}{c}0.0074 \\
(04.48 \%)\end{array}$ & $\begin{array}{l}0.1185 \\
(100 \%)\end{array}$ & $\begin{array}{l}0.1661 \\
(100 \%)\end{array}$ \\
\hline 2 & $\begin{array}{c}0.1022 \\
(84.03 \%)\end{array}$ & $\begin{array}{c}0.1627 \\
(90.39 \%)\end{array}$ & $\begin{array}{c}0.0194 \\
(15.97 \%)\end{array}$ & $\begin{array}{c}0.0173 \\
(09.61 \%)\end{array}$ & $\begin{array}{c}0.1136 \\
(93.42 \%)\end{array}$ & $\begin{array}{c}0.1724 \\
(95.74 \%)\end{array}$ & $\begin{array}{c}0.0080 \\
(06.58 \%)\end{array}$ & $\begin{array}{c}0.0077 \\
(04.26 \%)\end{array}$ & $\begin{array}{c}0.1216 \\
(100 \%)\end{array}$ & $\begin{array}{l}0.1801 \\
(100 \%)\end{array}$ \\
\hline
\end{tabular}

Notes : (share, compared with global inequality). 
Figure 3: Evolution of the QFs, conditional on parents' circumstances
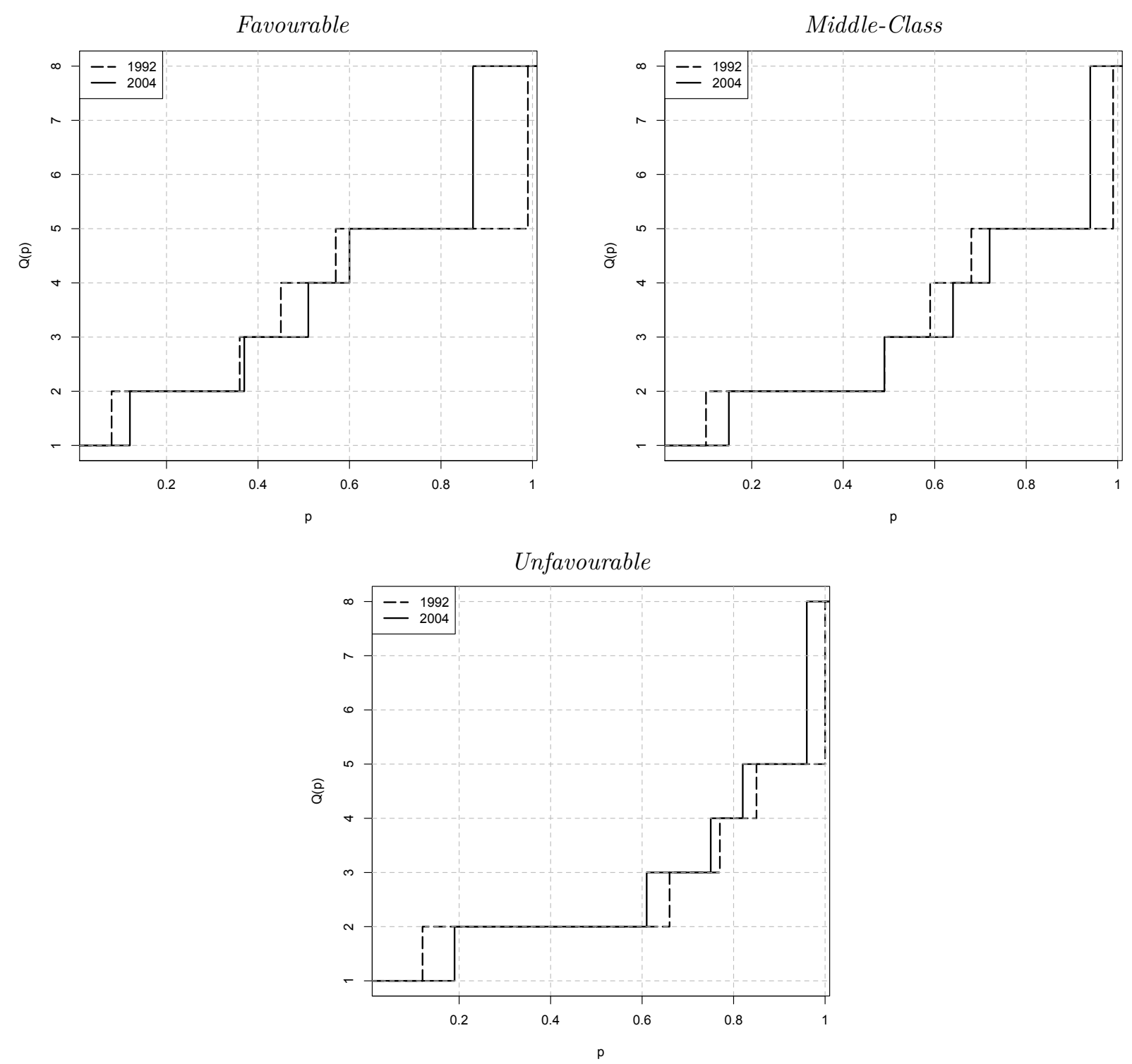
Figure 4: Within-Effort Opportunity RL (Deciles D1 to D9)
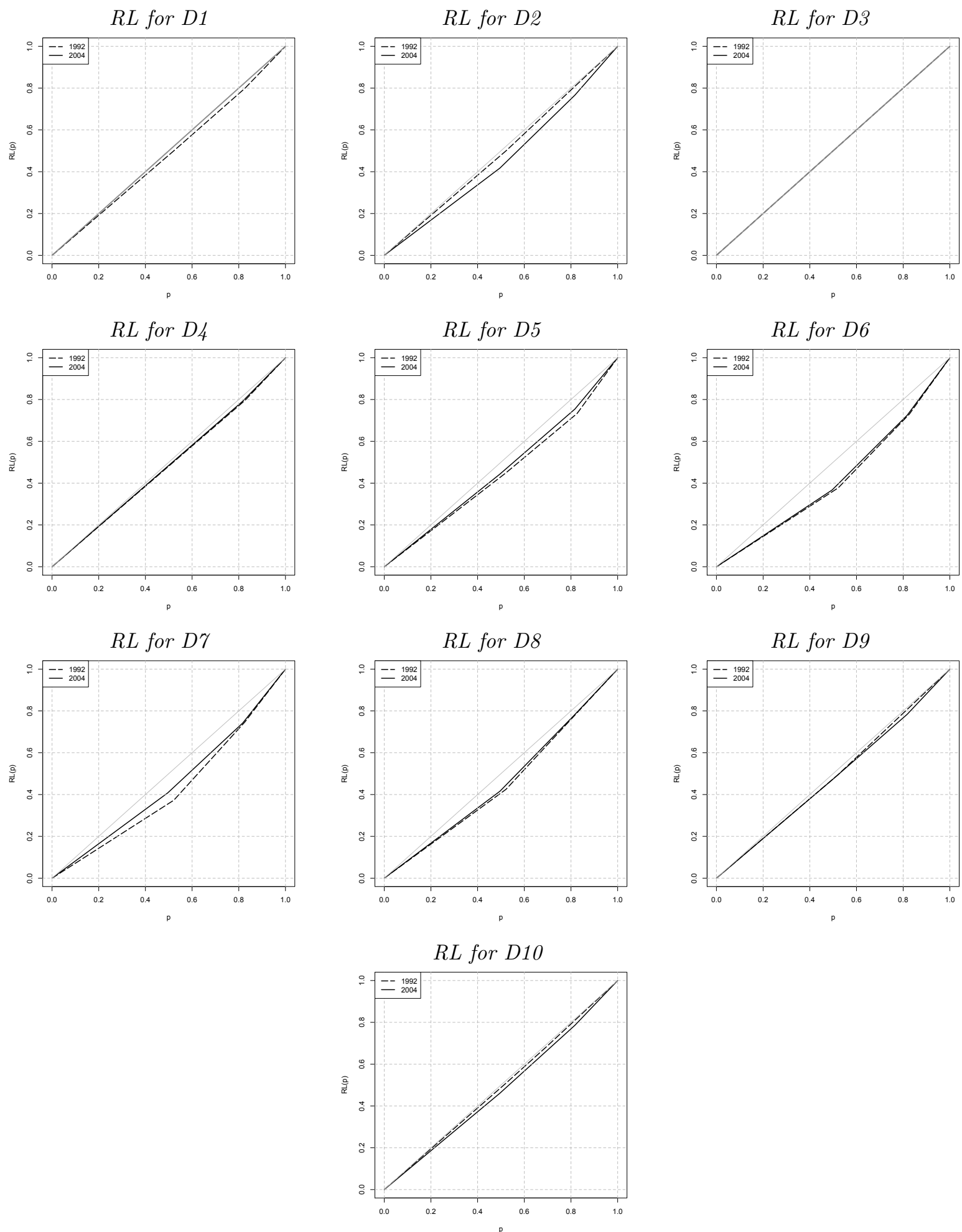
Figure 5: Between-Type Opportunity $R L$

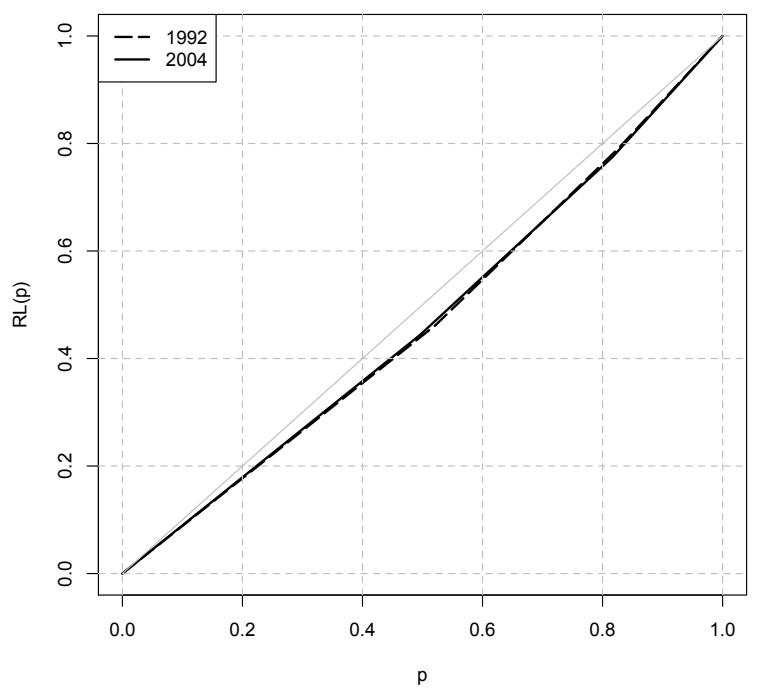

Figure 6: Inequality due to circumstances for different degrees of inequality aversion

Within-Effort Opportunity approach (WEO)

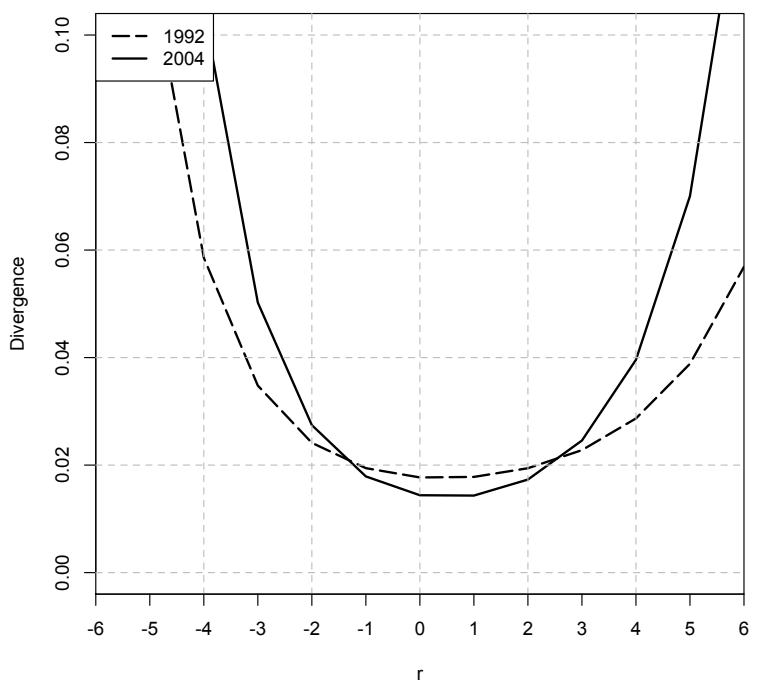

Between-Type Opportunity approach (BTO)

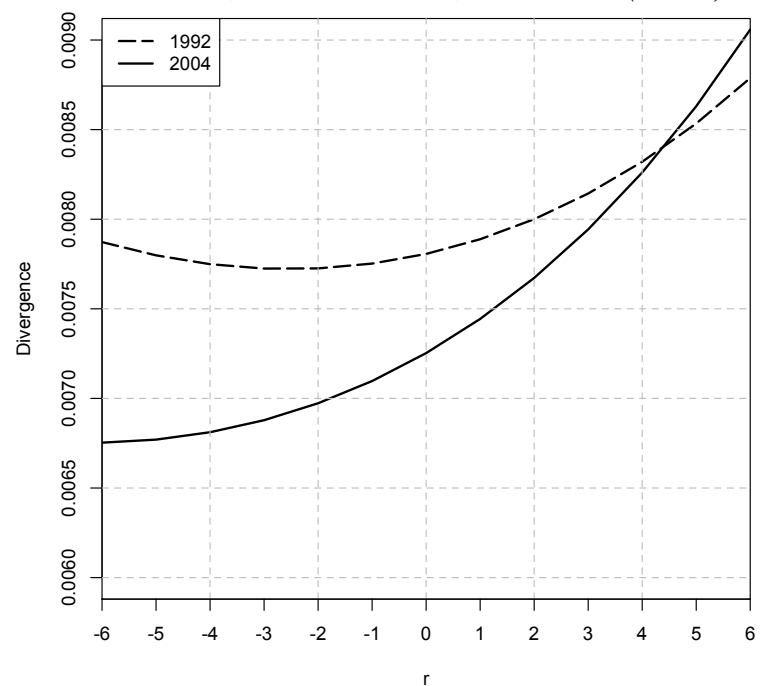


Table 6: Regression Models for 1992 and 2004

\begin{tabular}{|c|c|c|c|c|c|c|c|c|}
\hline \multirow[b]{2}{*}{ Variable } & \multicolumn{4}{|c|}{1992} & \multicolumn{4}{|c|}{2004} \\
\hline & Estimate & Std. Err. & t-Statistic & Prob. & Estimate & Std. Err. & t-Statistic & Prob. \\
\hline Intercept & 0.54704 & 0.03113 & 17.575 & 0.0000 & 0.50970 & 0.02520 & 20.223 & 0.0000 \\
\hline Father's SPC: Favourable & 0.10884 & 0.01516 & 7.1790 & 0.0000 & 0.08582 & 0.01045 & 8.2160 & 0.0000 \\
\hline Father's SPC: Middle-class & 0.02373 & 0.01778 & 1.3350 & 0.1826 & 0.06969 & 0.01341 & 5.1980 & 0.0000 \\
\hline Mother's SPC: Favourable & 0.02858 & 0.01624 & 1.7600 & 0.0786 & 0.05351 & 0.01115 & 4.7980 & 0.0000 \\
\hline Mother's SPC: Middle-class & 0.03840 & 0.01895 & 2.0270 & 0.0427 & 0.05832 & 0.01589 & 3.6700 & 0.0000 \\
\hline Gender: Man & 0.03608 & 0.01301 & 2.7740 & 0.0056 & 0.08210 & 0.00920 & 8.9250 & 0.0000 \\
\hline Secondary: Grade skipping & 0.09784 & 0.03466 & 2.8230 & 0.0048 & 0.07666 & 0.03003 & 2.5530 & 0.0107 \\
\hline Secondary: Normal & 0.05115 & 0.03022 & 1.6930 & 0.0906 & -0.00464 & 0.02478 & -0.1874 & 0.8513 \\
\hline Baccalauréat: Science & 0.24890 & 0.01712 & 14.536 & 0.0000 & 0.22764 & 0.01617 & 14.076 & 0.0000 \\
\hline Baccalauréat: Economics & 0.20375 & 0.02001 & 10.181 & 0.0000 & 0.28994 & 0.01379 & 21.089 & 0.0000 \\
\hline Baccalauréat: Literature & 0.14173 & 0.02166 & 6.5440 & 0.0000 & 0.46027 & 0.01209 & 38.204 & 0.0000 \\
\hline Orientation: Selective & 0.52889 & 0.02162 & 24.465 & 0.0000 & 0.41997 & 0.01562 & 26.893 & 0.0000 \\
\hline \multirow[t]{8}{*}{ Orientation: Unselective } & 0.14792 & 0.01480 & 9.9940 & 0.0000 & 0.09817 & 0.01059 & 9.2680 & 0.0000 \\
\hline & \multicolumn{2}{|l|}{$R$-squared } & \multicolumn{2}{|l|}{0.2597} & \multicolumn{2}{|l|}{$R$-squared } & 0.2368 & \\
\hline & \multirow{2}{*}{\multicolumn{2}{|c|}{$\begin{array}{l}\text { Adjusted } R \text {-squared } \\
\text { S.E. of regression }\end{array}$}} & \multicolumn{2}{|l|}{0.2580} & \multicolumn{2}{|c|}{ Adjusted $R$-squared } & 0.2361 & \\
\hline & & & \multicolumn{2}{|l|}{0.4410} & \multicolumn{2}{|c|}{ S.E. of regression } & 0.5204 & \\
\hline & \multicolumn{2}{|c|}{ Sum squared resid. } & 1016.7 & & \multicolumn{2}{|c|}{ Sum squared resid. } & 3806.4 & \\
\hline & \multicolumn{2}{|c|}{ Log likelihood } & \multicolumn{2}{|l|}{-3139.1} & Log likelih & & -10766 & \\
\hline & \multicolumn{2}{|c|}{ F-statistic } & \multicolumn{2}{|l|}{152.85} & \multicolumn{2}{|c|}{$F$-statistic } & 363.4 & \\
\hline & \multicolumn{2}{|c|}{$\operatorname{Prob}(F$-statistic) } & \multicolumn{2}{|l|}{0.0000} & \multicolumn{2}{|c|}{$\operatorname{Prob}(F-$-statistic $)$} & 0.0000 & \\
\hline
\end{tabular}

Figure 7: Lorenz curves for the counterfactual approach, scenario S1

Lorenz curves / actual and ref. distributions

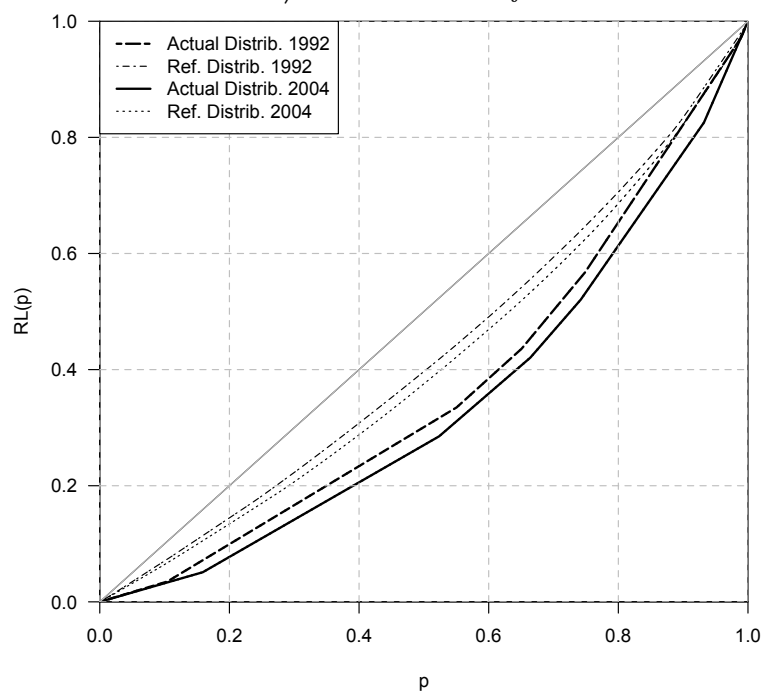

Unfairness Lorenz curves

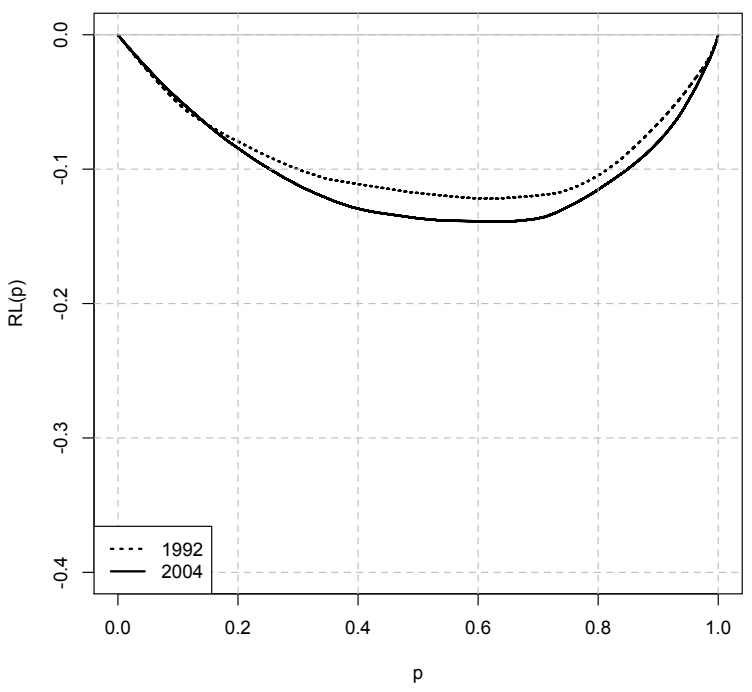


Table 7: Unfairness indices according to the compensation scenario

\begin{tabular}{|c|c|c|c|c|}
\hline Scenarios & Indices & 1992 & 2004 & Difference \\
\hline \multirow{6}{*}{ S1 } & Unfairness Gini & 0.1770 & 0.1990 & 0.0221 \\
\hline & MN Divergence $(r=-2)$ & 0.1363 & 0.2034 & 0.0671 \\
\hline & MN Divergence $(r=-1)$ & 0.0896 & 0.1228 & 0.0332 \\
\hline & MN Divergence $(r=0)$ & 0.0663 & 0.0841 & 0.0179 \\
\hline & MN Divergence $(r=1)$ & 0.0558 & 0.0681 & 0.0123 \\
\hline & MN Divergence $(r=2)$ & 0.0538 & 0.0680 & 0.0142 \\
\hline \multirow{6}{*}{$\mathrm{S} 2$} & Unfairness Gini & 0.1805 & 0.2075 & 0.0270 \\
\hline & MN Divergence $(r=-2)$ & 0.1429 & 0.2191 & 0.0762 \\
\hline & MN Divergence $(r=-1)$ & 0.0941 & 0.1336 & 0.0396 \\
\hline & MN Divergence $(r=0)$ & 0.0696 & 0.0922 & 0.0226 \\
\hline & MN Divergence $(r=1)$ & 0.0585 & 0.0748 & 0.0163 \\
\hline & MN Divergence $(r=2)$ & 0.0562 & 0.0743 & 0.0181 \\
\hline \multirow{6}{*}{ S3 } & Unfairness Gini & 0.1910 & 0.2079 & 0.0169 \\
\hline & MN Divergence $(r=-2)$ & 0.1546 & 0.2184 & 0.0638 \\
\hline & MN Divergence $(r=-1)$ & 0.1034 & 0.1334 & 0.0300 \\
\hline & MN Divergence $(r=0)$ & 0.0775 & 0.0922 & 0.0147 \\
\hline & MN Divergence $(r=1)$ & 0.0656 & 0.0749 & 0.0093 \\
\hline & MN Divergence $(r=2)$ & 0.0630 & 0.0747 & 0.0117 \\
\hline \multirow{6}{*}{ S4 } & Unfairness Gini & 0.2353 & 0.2968 & 0.0615 \\
\hline & MN Divergence $(r=-2)$ & 0.1864 & 0.2779 & 0.0915 \\
\hline & MN Divergence $(r=-1)$ & 0.1362 & 0.1965 & 0.0604 \\
\hline & MN Divergence $(r=0)$ & 0.1104 & 0.1592 & 0.0488 \\
\hline & MN Divergence $(r=1)$ & 0.0986 & 0.1474 & 0.0488 \\
\hline & MN Divergence $(r=2)$ & 0.0965 & 0.1558 & 0.0593 \\
\hline \multirow{6}{*}{ S5 } & Unfairness Gini & 0.2643 & 0.3170 & 0.0527 \\
\hline & MN Divergence $(r=-2)$ & 0.1920 & 0.2849 & 0.0929 \\
\hline & MN Divergence $(r=-1)$ & 0.1470 & 0.2072 & 0.0602 \\
\hline & MN Divergence $(r=0)$ & 0.1262 & 0.1740 & 0.0478 \\
\hline & MN Divergence $(r=1)$ & 0.1195 & 0.1671 & 0.0476 \\
\hline & MN Divergence $(r=2)$ & 0.1230 & 0.1815 & 0.0586 \\
\hline
\end{tabular}

